\title{
Article \\ Transverse Cracking of Concrete Base Plate in CRTS III Ballastless Track Structure: Effects of Environmental Boundary Conditions
}

\author{
Weiqiang Guo ${ }^{1}$, Xin Huang ${ }^{2}$, Lijun Zhao ${ }^{2}$ and Ya Wei ${ }^{1, *}$ \\ 1 Key Laboratory of Civil Engineering Safety and Durability of China Education Ministry, \\ Department of Civil Engineering, Tsinghua University, Beijing 100084, China; gwq21@mails.tsinghua.edu.cn \\ 2 China Railway 24th Bureau Group Bridge Construction Co., Ltd., Nanchang 330100, China; \\ 15201342510@163.com (X.H.); cswbjzxy@163.com (L.Z.) \\ * Correspondence: yawei@tsinghua.edu.cn
}

check for updates

Citation: Guo, W.; Huang, X.; Zhao, L.; Wei, Y. Transverse Cracking of Concrete Base Plate in CRTS III Ballastless Track Structure: Effects of Environmental Boundary Conditions. Appl. Sci. 2021, 11, 10400. https:// doi.org/10.3390/app112110400

Academic Editor: Dario De Domenico

Received: 1 October 2021

Accepted: 28 October 2021

Published: 5 November 2021

Publisher's Note: MDPI stays neutral with regard to jurisdictional claims in published maps and institutional affiliations.

Copyright: (c) 2021 by the authors. Licensee MDPI, Basel, Switzerland. This article is an open access article distributed under the terms and conditions of the Creative Commons Attribution (CC BY) license (https:// creativecommons.org/licenses/by/ $4.0 /)$.
Abstract: The cast-in-place concrete base plate is a main member of the China Railway Track System (CRTS) III ballastless track structure that is prone to generating early transverse cracking. Such cracks can dramatically affect the performance and service life of the railway track structure. This study investigated the influence of temperature and moisture boundary conditions on early cracking behavior of the CRTS III base plate by using approaches of both in situ measurements and numerical modelling. In-site measurements of strain and temperature were made in four test series of CRTS III base plates under the same natural environmental condition but cured with different regimes, and a total of 96 measuring positions were monitored for up to 150 days. The results showed that the strain magnitude and distribution in the field base plate, the initial time at cracking, and the observed cracking pattern varied significantly between the different test series. In order to understand the mechanisms that create these transverse cracks and to provide guidelines for the current curing strategy during construction, the characteristics of temperature-induced and moisture-induced stresses were analyzed by using 3D numerical modelling and by considering early-age concrete creep properties, meteorological factors, and the influence from environmental boundary conditions. The calculated results revealed that early-age transverse cracking in CRTS III base plate depends more on drying shrinkage stress than temperature stress. By conducting this study, we expect to provide guidance for reducing or eliminating early cracks of CRTS III concrete base plate.

Keywords: concrete plate; CRTS III ballastless track; transverse cracking; environmental boundary condition; in-site strain measurement

\section{Introduction}

Due to high reliability and stability, ballastless slab track systems have been widely utilized in high-speed railways all over the world. In China, the CRTS III (China Railway Track System III) slab ballastless track structure is the third type and the latest slab track system, and more than $5000 \mathrm{~km}$ has been built as of October 2020 [1]. The steam-cured concrete precast slab, the self-compacting concrete (SCC) filling layer, the isolation layer (geotextile material), and the concrete base plates are the main components of the CRTS III slab track, which is a laminated structure. According to field investigations [2,3], transverse base plate cracking is one of the major forms of slab track defects. Figure 1 shows typical transverse cracks in the CRTS III type base plate. These cracks are located on the surface and at the middle portion of the base plate, and a few of them are extended to full depth. The field crack surveys conducted at the Beijing-Tangshan High-speed Railway revealed that most transverse cracks were initiated within a month after a specified 14-day wet-curing period. After about 2 months of casting, up to $50 \%$ cracking probability was reported. Undoubtedly, the formation of early cracks results in concrete deterioration and increases maintenance costs of a track structure. Therefore, the causes and prevention of early base plate cracking needs to be well understood. 


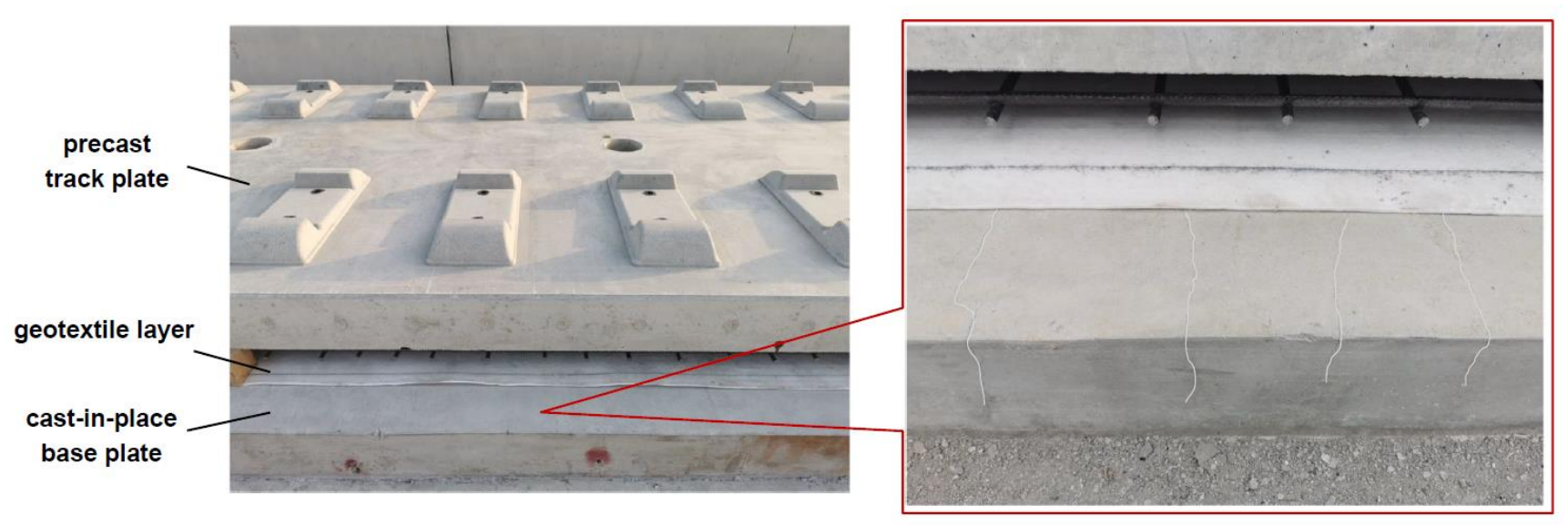

Figure 1. Typical transverse cracking in CRTS III type base plate.

The concrete base plate of high-speed railway ballastless track system is designed with the aim of supporting the upper components and transmitting train loads to the subgrade or the elevated bridge foundation. The current study focuses on the base plate resting on simply-supported prestressed girder bridges, which are a widely utilized structure form because bridge foundations make up a great percentage of foundations of the highspeed railways in China. It is noted that the CRTS III base plate has varying dimensions in design and mainly depends on the dimension of the precast box-girder. The base plate investigated in this study is $5.65 \mathrm{~m}$ in length, $2.90 \mathrm{~m}$ in width, and $0.2 \mathrm{~m}$ in thickness, and it is reinforced by two layers of steel mesh inside. It is a well-known fact that transverse cracks in a plate structure of concrete are caused by longitudinal tensile stresses. These stresses are highly related to thermal, shrinkage, and creep strains. On the one hand, the precast bridge foundations restrain the natural thermal and shrinkage movement of the concrete. On the other hand, the temperature field of a concrete plate under natural environment is rarely uniform or linearly distributed. Drying shrinkage is also nonlinearly distributed along the plate depth. Consequently, non-uniform shrinkage and temperature deformation cause stresses even without external restraint. A numerical study has shown that shrinkage strains are caused by drops in relative humidity (RH) by $1 \%$ is $15 \times 10^{-6}$ to $20 \times 10^{-6}$, which appears larger than the strain caused by temperature decrease by $1^{\circ} \mathrm{C}$ [4]. In the literature [5-9], a strong emphasis is given to the non-uniform distribution of dryinginduced stress within the concrete, but these works are either based on indoor tests or are only focused on numerical simulations. As a result, the previous studies provide limited guidance to the problem in current research because of dissimilar humidity diffusion performance and mechanical properties between the cast-in-place fresh concrete base plate and the prefabricated concrete bridge foundation and some other special characteristics of the CRTS III slab track.

Previous studies have also revealed that the most important construction-related factors affecting transverse cracking in plate structures of (reinforced) concrete involve weather and curing [10-13]. Adverse weather includes strong wind, high and low temperatures, and low-humidity conditions [14]. Under these conditions, ineffective or delayed curing was the most common reason suggested by railway engineering technicians for early transverse cracking in base plate. Curing practice affects the properties of hardening concrete such as strength, volume stability, durability, and resistance to freezing and thawing [15-19]. Inadequate curing inevitably increases the potential or severity of transverse cracking in concrete base plate. Although railway construction enterprises had a standard regime of curing CRTS III concrete base plate casting on bridge foundations, early transverse cracks were not well controlled in practice.

Evaluating the stress and strain developments of CRTS III base plates during the curing stage is critical for optimizing the curing regime in order to reduce early cracking phenomena. This is a complex problem and should be solved by considering the concrete 
shrinkage and thermal deformations influenced by environmental boundary conditions, the structural constraint from bridge foundations, and also the early-age concrete creep that is crucial for stress prediction [20]. Despite the importance of this problem, few numerical studies or field data are available in literature. For this reason, this study investigated CRTS III concrete base plate transverse cracking with field instrumentation, cracking monitoring, and numerical modelling. Full-scale CRTS III base plates were constructed, instrumented, and subjected to different curing regimes. The actual effects of environmental boundary conditions on strain development and early transverse cracking behavior of the base plate were assessed by field strain measurements and crack inspections. The environmental boundary conditions in field, material properties, and construction factors were properly simulated in stress calculations in order to provide more accurate insights into the early cracking behavior of CRTS III concrete base plates under different curing conditions. This study suggests the following: (1) Drying shrinkage induced stress is much more serious than thermal induced stress; thus, the former may be the primary cause for early transverse cracks. (2) Prolonged sealed-curing may cause decreased magnitude of shrinkage gradients when dried to a given $\mathrm{RH}$ and, thus, results in lower potentials of cracking.

\section{Methodology}

\subsection{Field Instrumentation}

The behavior of the field concrete base plate was evaluated through temperature and strain measurements. A total of eight full-scale CRTS III concrete base plates were instrumented, with two plates for each curing regime. Each plate was instrumented with twelve vibrating wire strain gauges (VWSGs) for the measurements of strain and temperature variations at different locations. The length of the VWSG was $143 \mathrm{~mm}$. Strain measurement accuracy was $\pm 2 \mu \varepsilon$, and temperature measurement accuracy was $\pm 0.1^{\circ} \mathrm{C}$. This type of strain gauge was selected mainly because temperature data were simultaneously recorded by it, and temperature compensation relative to the measured strain was automatically calibrated by a software designed for it.

Figure $2 \mathrm{a}, \mathrm{b}$ shows the arrangement of the VWSGs on the plane and in the depth direction, respectively. Considering that early transverse cracks were generally localized in the middle portion of a base plate, seven VWSGs were placed in the high-cracking-tendency mid-plate cross-section (positions A, B, and E), These strain gauges were used to monitor strain developments within the concrete up to the occurrence of first cracking. At positions $\mathrm{A}$ and $\mathrm{B}$, the VWSGs were placed in the top, middle, and bottom layer to measure strain and temperature distributions along the plate depth. The other five VWSGs were placed at the edge (positions C and F) and the corner (position D), and the strain variations were expected to be significantly affected by the surrounding environment due to lower degrees of restraint at these locations. All field instrumentation was connected to a data acquisition system (DAS) remotely controlled by a laptop computer. The interval of data recording was $20 \mathrm{~min}$.

\subsection{Curing Schemes and Field Test Procedure}

According to recent specifications [21,22] published by China Railway Corp., the minimum time of wet-curing with compound geotextile for CRTS III base plate is 14 days. Hence, a standardized curing regime adopted by most railway construction enterprises includes a 14-day wet curing period and subsequent sealed curing for a few days. However, it is believed that the optimum curing scheme can reduce early-age transverse cracking, which is the motivation of the current research investigation. 
(a)

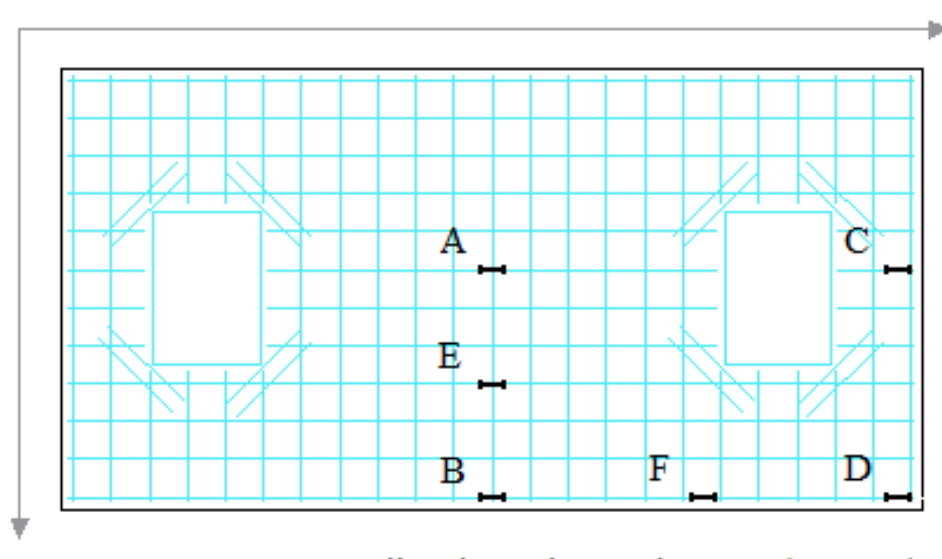

Lareral

$\longmapsto$ vibrating wire strain gage (VWSG)
Longitudinal direction

(b)

direction

Section A, B

Section C, D

Section E, F
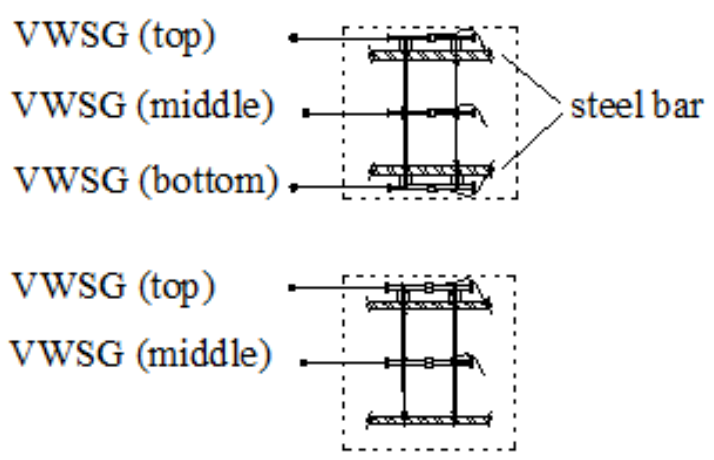

VWSG (top)

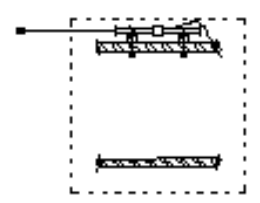

Figure 2. The arrangement of VWSG: (a) on the plane and (b) in depth direction.

The test site is located in Tianjin, China. A total of eight full-size, cast-in-place concrete base plates were constructed in cold seasons and divided into four test series, as shown in Figure 3 and Table 1. During the tested days, the daily maximum temperature was $18.5{ }^{\circ} \mathrm{C}$, and the daily minimum temperature was $-15^{\circ} \mathrm{C}$. For the base plates in Series I, the curing stage consisted of a 14-day wet curing period and a subsequent 6-day sealed curing period. It is almost a standardized curing regime adopted in construction practice. Compound geotextile covers were used during wet and sealed curing. It has a double-layer structure formed by an outer geotextile layer and an inner polyethylene film; thus, it can stably retain high humidity by maintaining concrete. However, as noted above, early transverse cracks often occurred under this curing regime (Series I). In Series II and III, the duration of sealed curing was prolonged to 31 days and 106 days, respectively. In Series IV, after 3 days of casting, two layers of cotton quilts were covered on the top of the geotextile cover in order to enhance temperature preservation effects. 


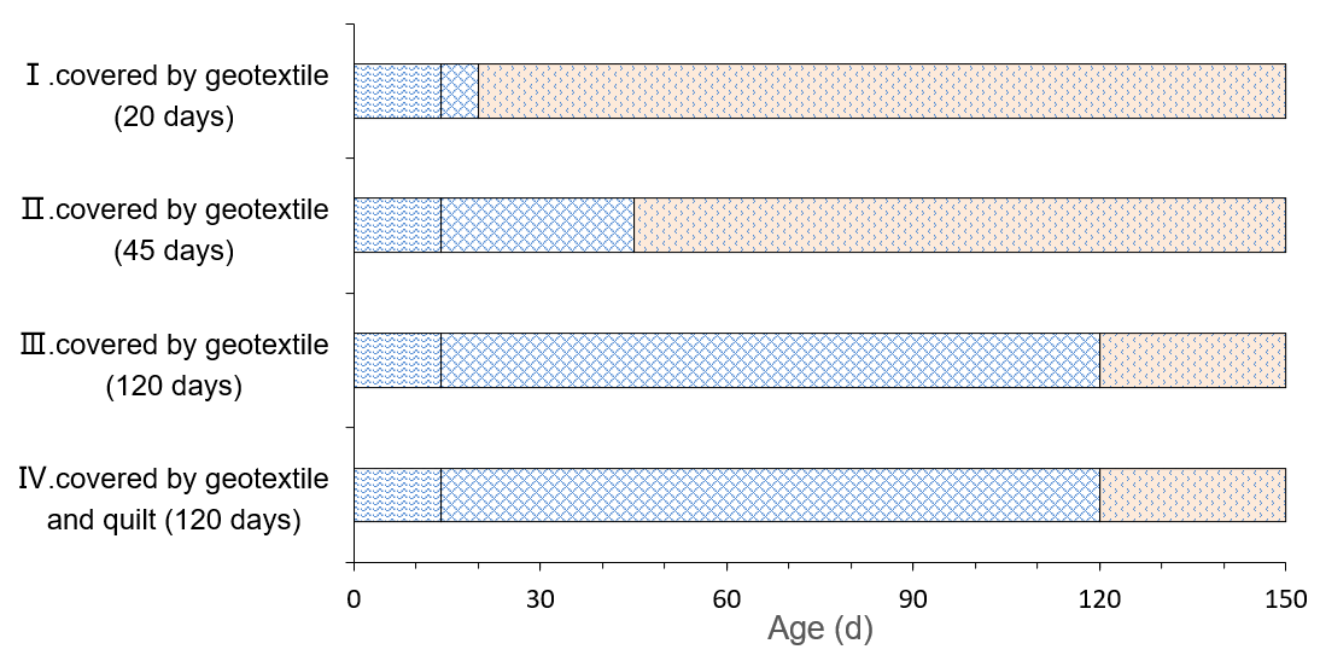

Figure 3. Curing regimes adopted in the field test.

Table 1. Curing regimes adopted in the field test.

\begin{tabular}{cccccc}
\hline $\begin{array}{c}\text { Test } \\
\text { Series }\end{array}$ & $\begin{array}{c}\text { Plate } \\
\text { Quantity }\end{array}$ & $\begin{array}{c}\text { Wet-Curing } \\
\text { Time (Days) }\end{array}$ & $\begin{array}{c}\text { Sealed-Curing } \\
\text { Time (Days) }\end{array}$ & $\begin{array}{c}\text { Total Curing } \\
\text { Time (Days) }\end{array}$ & $\begin{array}{c}\text { Covering Materials used in } \\
\text { the Curing Period }\end{array}$ \\
\hline I & 2 & 14 & 6 & 20 & composite geotextile \\
\hline II & 2 & 14 & 31 & 45 & composite geotextile \\
\hline III & 2 & 14 & 106 & 120 & composite geotextile \\
\hline IV & 2 & 14 & 106 & 120 & composite geotextile + quilt \\
\hline
\end{tabular}

The procedure of in-site CRTS III base plate construction is shown in Figure 4. This base plate was designed to be reinforced with a $250 \mathrm{~mm} \times 250 \mathrm{~mm}$ steel bar mesh at the top and bottom layers. The concrete cover to the top and bottom meshes of reinforcement was $50 \mathrm{~mm}$ thick. Prior to concrete casting, the two layers of steel mesh were placed on the bridge foundation, which facilitated the positioning of the strain gauges to the desired locations. The top, middle, and bottom VWSGs were instrumented at depths of 25, 100, and $175 \mathrm{~mm}$ from the top surface of the base plate (Figure 4a). All these plates were cast (Figure $4 \mathrm{~b}$ ) on 9 November 2020 by using the same concrete mixture proportion presented in Table 2. The slump of fresh concrete was maintained in the range of 120 to $160 \mathrm{~mm}$ for ease of casting and consolidation. Wet-curing was initiated after the final set of the concrete. After $10 \mathrm{~h}$ of casting, a sheet of compound geotextile was used to cover the top surfaces of these base plates (Figure 4c). Three days later, the steel side formwork was removed. The side surfaces of the plates were covered with the same geotextile in order to avoid, as much as possible, any water loss from its sides. All these concrete base plates were cured under water-saturated geotextile cover for 14 days (Figure $4 \mathrm{~d}$ ), followed by a period of sealed curing that corresponded to a curing condition in the absence of external water sources (Figure 4e). After the sealed curing period (note that the duration of this period varied among the different test series), the base plates were exposed to the natural environment directly (Figure 4f). 


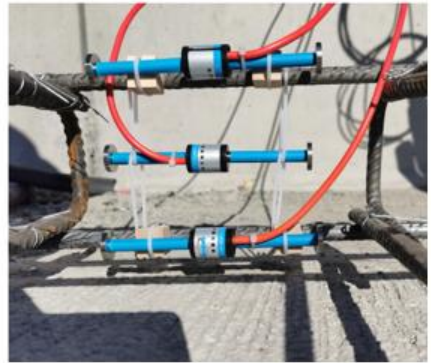

(a) instrumented strain gauge

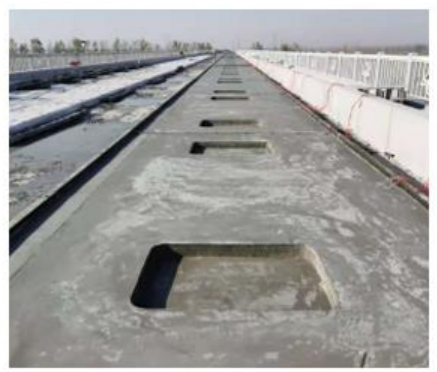

(f) exposed to drying

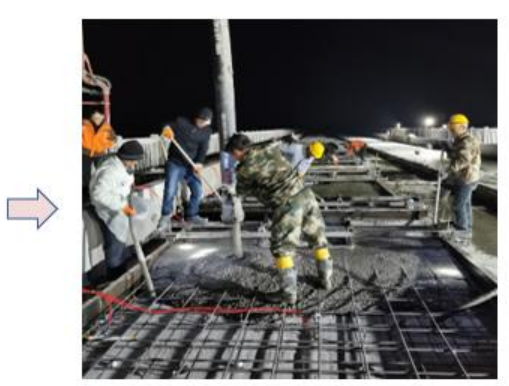

(b) base plate casting

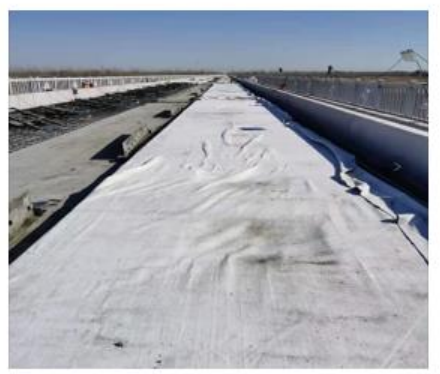

(e) sealed-curing

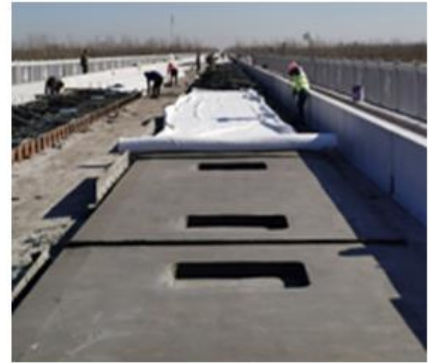

(c) demolding

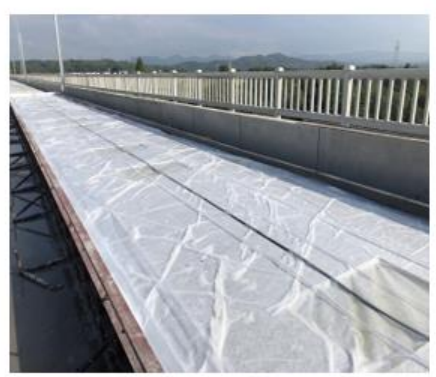

(d) wet-curing
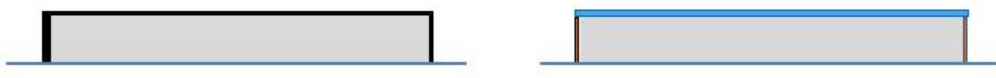

Figure 4. The main flows of in-site CRTS III base plate construction and curing.

Table 2. Mixture proportion of base plate concrete.

\begin{tabular}{cccccccc}
\hline $\begin{array}{c}w / b \\
\text { Ratio }\end{array}$ & $\begin{array}{c}\text { Cement } \\
\left(\mathbf{k g} / \mathbf{m}^{3}\right)\end{array}$ & $\begin{array}{c}\text { Fly Ash } \\
\left(\mathbf{k g} / \mathbf{m}^{\mathbf{3}}\right)\end{array}$ & $\begin{array}{c}\text { Water } \\
\left(\mathbf{k g} / \mathbf{m}^{3}\right)\end{array}$ & $\begin{array}{c}\text { Coarse } \\
\text { Aggregate } \\
\left(\mathbf{k g} / \mathbf{m}^{\mathbf{3}}\right)\end{array}$ & $\begin{array}{c}\text { Sand } \\
\left(\mathbf{k g} / \mathbf{m}^{3}\right)\end{array}$ & $\begin{array}{c}\text { Air Entraining } \\
\text { Agent }\left(\mathbf{k g} / \mathbf{m}^{\mathbf{3}}\right)\end{array}$ & $\begin{array}{c}\text { Super } \\
\mathbf{P l a s t i c i z e r} \\
\left(\mathbf{k g} / \mathbf{m}^{3}\right)\end{array}$ \\
\hline 0.34 & 309 & 132 & 150 & 1046 & 756 & 2.2 & 4.85 \\
\hline
\end{tabular}

\subsection{Numerical Procedure}

The potential for base plate cracking greatly depends on the magnitude of tensile stress induced by shrinkage and thermal contraction since humidity and temperature changes may produce identical stresses in a plate structure of hardening concrete. A numerical procedure was devised to calculate shrinkage and thermal stresses. It included a temperature model considering hydration heat of cement and heat transfer between concrete and the surrounding environment, a moisture model that could capture the relative humidity development of early-age concrete, and a mechanical model to compute strains and stresses. Concrete creep effect was pronounced at an early age, and it was properly considered in the mechanical model.

For heat transfer in concrete, the governing equation is described as follows:

$$
\rho c \dot{T}=\nabla \cdot\left(k_{T} \cdot \nabla T\right)+\dot{Q}
$$

where $\rho$ is the mass density of concrete $\left(\mathrm{kg} / \mathrm{m}^{3}\right) ; c$ is the specific heat capacity of concrete $\left(\mathrm{J} / \mathrm{kg} \cdot{ }^{\circ} \mathrm{C}\right) ; T$ is the temperature of concrete $\left({ }^{\circ} \mathrm{C}\right) ; k_{T}$ is the thermal conductivity of concrete; $\left(\mathrm{W} / \mathrm{m} \cdot{ }^{\circ} \mathrm{C}\right)$ and $\dot{Q}$ is the rate of hydration heat generation $\left(\mathrm{W} / \mathrm{m}^{3} \cdot{ }^{\circ} \mathrm{C}\right)$.

The rate of hydration heat is expressed by an Arrhenius law of the following form [23]:

$$
\dot{Q}=a f(\alpha) e^{-\frac{E_{a}}{R T}}
$$

where is the maximum value of the heat generation rate $(\mathrm{J} / \mathrm{s}) ; E_{a}$ is the activation energy $(\mathrm{J} / \mathrm{mol}) ; R$ is the universal gas constant $\left(8.314 \mathrm{~J} / \mathrm{mol} \mathrm{K}^{-1}\right)$; and $f(\alpha)$ describes the evolution of the normalized heat generation rate as a function of the hydration degree $\alpha$. 
For moisture diffusion in concrete, the governing equation is as follows:

$$
\dot{H}=\nabla \cdot[D(H) \cdot \nabla H]-\dot{H}_{\mathrm{s}}
$$

where $H$ is the RH of concrete, $H_{S}$ is the rate of RH drop due to self-desiccation, and $D(H)$ is the moisture diffusivity $\left(\mathrm{m}^{2} / \mathrm{s}\right)$. According to [24], $D(H)$ can be approximated by the following:

$$
D(H)=D_{1}\left(\alpha_{0}+\frac{1-\alpha_{0}}{1+\left(1-h / 1-h_{c}\right)^{r}}\right)
$$

where $D_{1}$ and $h_{c}$ are rare empirical parameters. The default values recommended by the fib Model Code [25] were used in this study.

With simulated results of temperature and relative humidity field, thermal and hygrometric (i.e., shrinkage or swelling) strains can be calculated by the following relations:

$$
\dot{\varepsilon}^{T}(t)=\alpha_{T} \dot{T}(t), \quad \dot{\varepsilon}^{s h}(t)=k_{s h} \dot{H}(t)
$$

where $\alpha_{T}$ is the coefficient of thermal expansion, and $k_{s h}$ is the shrinkage coefficient of the concrete that $\alpha_{T}$ depends on $T$ and $k_{s h}$ depends on $H$ but only weakly. As simplification, they can be assumed to be constant [26].

For step-by-step finite element analysis of stress, an incremental form of the constitutive equation used for coding needs to be deduced. The stress-dependent strains due to elasticity and concrete creep can be characterized by a compliance function obtained from creep tests. Since early-age concrete creep greatly dependents on the evolution of internal humidity and temperature and, hence, further depends on weather conditions and on the adopted curing regime, properly considering the effects of temperature and humidity on creep strain is required. To this end, the microprestress solidification (MPS) theory-based creep model was adapted. The concept of microprestress was conceived by Bažant et al. [26,27] in order to reproduce the drying creep effect (or Pickett effect) and the transitional thermal creep effect. Due to the complicated calculation of the MPS theorybased creep model, its detailed derivation and three-dimensional tensorial generalization for numerical programming are not described in this study, which can be found in [28-30].

A three-dimensional FE model of a base plate of reinforced concrete and its supporting girder was developed. The FE model reflecting thermal, hygrometric, and structural loads and responses was established in ABAQUS v6.14. The transient thermal analysis module was used to simulate the temperature field of the base plate and girder bridge system. The elements used for thermal analysis were the DC3D20 type for the base plate and the girder and the DC1D2 type for the steel mesh. The analysis module and element types used for humidity field analysis were the same as those for thermal analysis due to the mathematical similarities between the governing equations for heat transfer and moisture diffusion, i.e., Equations (1) and (3). A user-defined material subroutine (UMAT) incorporating the aforementioned MPS creep model was developed for structural analysis [31]. The meshed model is shown in Figure 5. The element size of the base plate was taken as $25 \mathrm{~mm} \times 25 \mathrm{~mm} \times 50 \mathrm{~mm}$ based on mesh sensitivity analysis. Only half of the bridge girder was modelled due to symmetry in order to reduce computation time. 

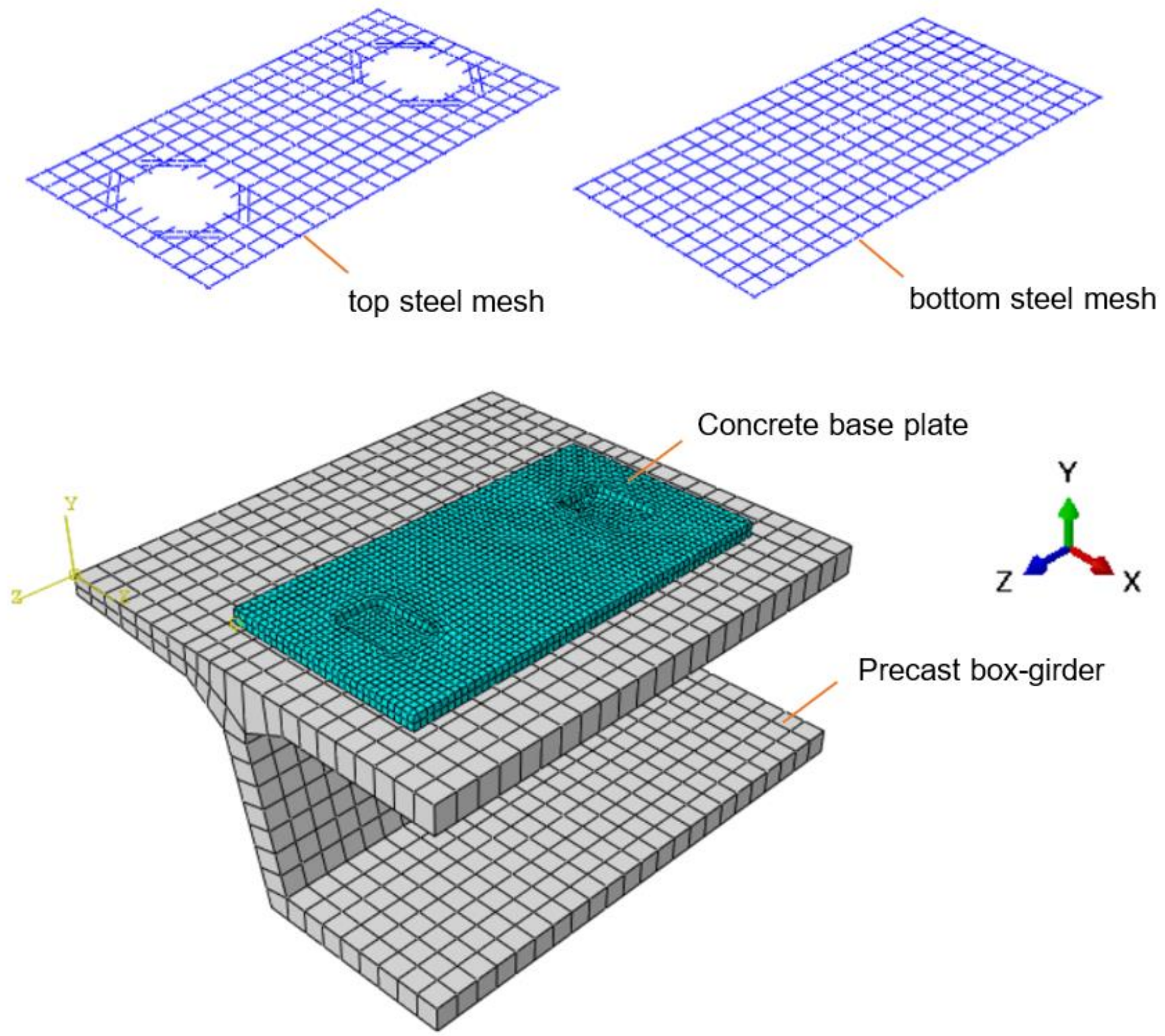

\section{Precast box-girder}

Figure 5. Finite element model of CRTS III base plate on bridge foundation.

\subsection{Selection of Boundary Conditions}

The boundary conditions of the concrete base plate were defined with respect to thermal, moisture, and structural problems, which are illustrated in Figure 6.

For thermal analysis, the convection can be expressed by the following:

$$
q_{c}=\beta_{c}\left(T_{\text {sur }}-T_{\text {air }}\right)
$$

where $q_{c}$ is the convective heat flux $\left(\mathrm{W} / \mathrm{m}^{2}\right) ; \beta_{c}$ is the convective coefficient $\left(\mathrm{W} / \mathrm{m}^{2} \cdot{ }^{\circ} \mathrm{C}\right)$; and $T_{\text {sur }}$ and $T_{\text {air }}$ are the concrete surface and air temperatures $\left({ }^{\circ} \mathrm{C}\right)$, respectively. The convection coefficient is largely dependent on wind speed $v(\mathrm{~m} / \mathrm{s})$ and it can be estimated as $\beta_{c}=2.6\left(\sqrt[4]{\left|T_{\text {sur }}-T_{\text {air }}\right|}+1.54 v\right)$ [32]. 


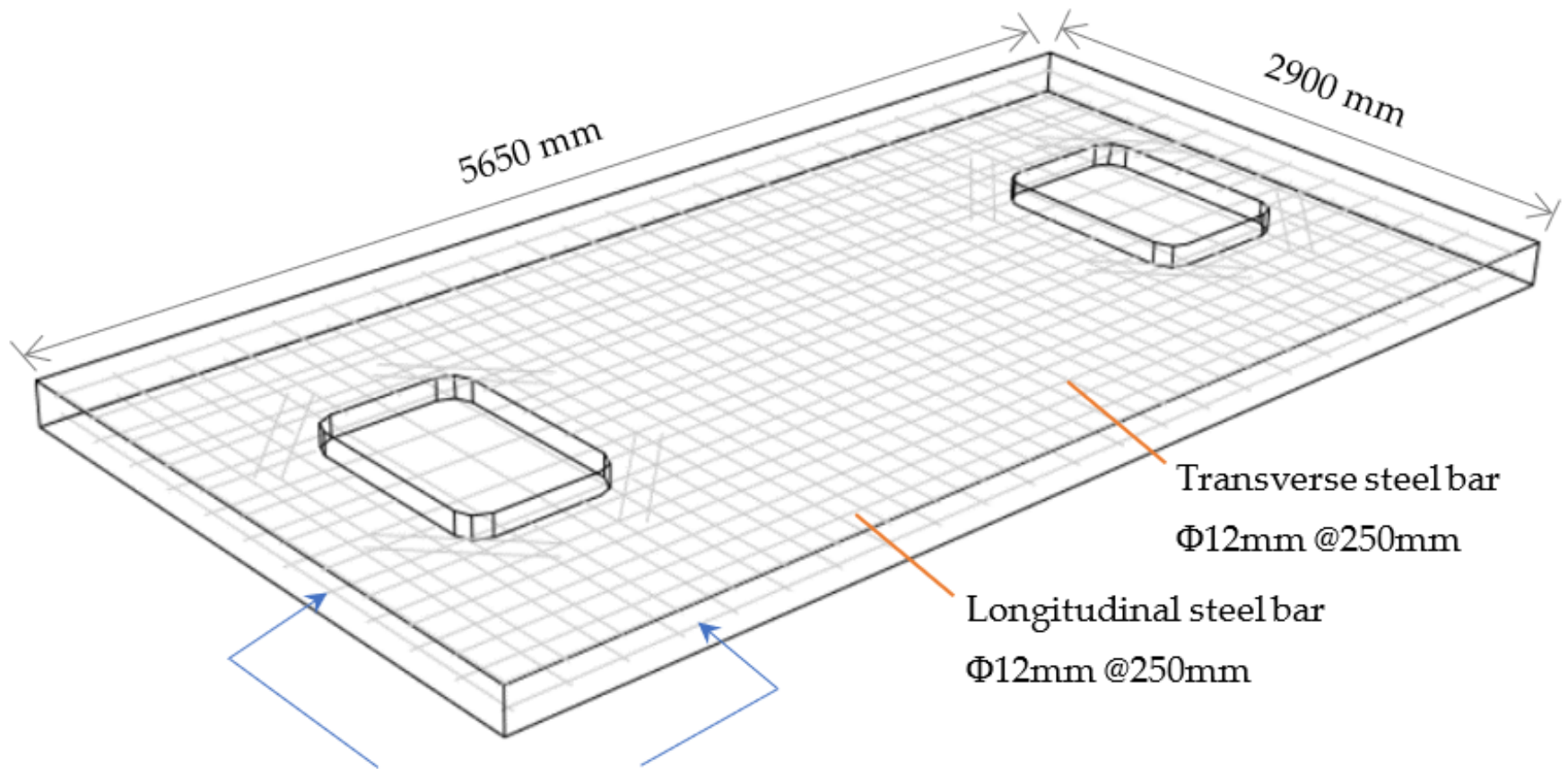

Heat convection and moisture boundary interface

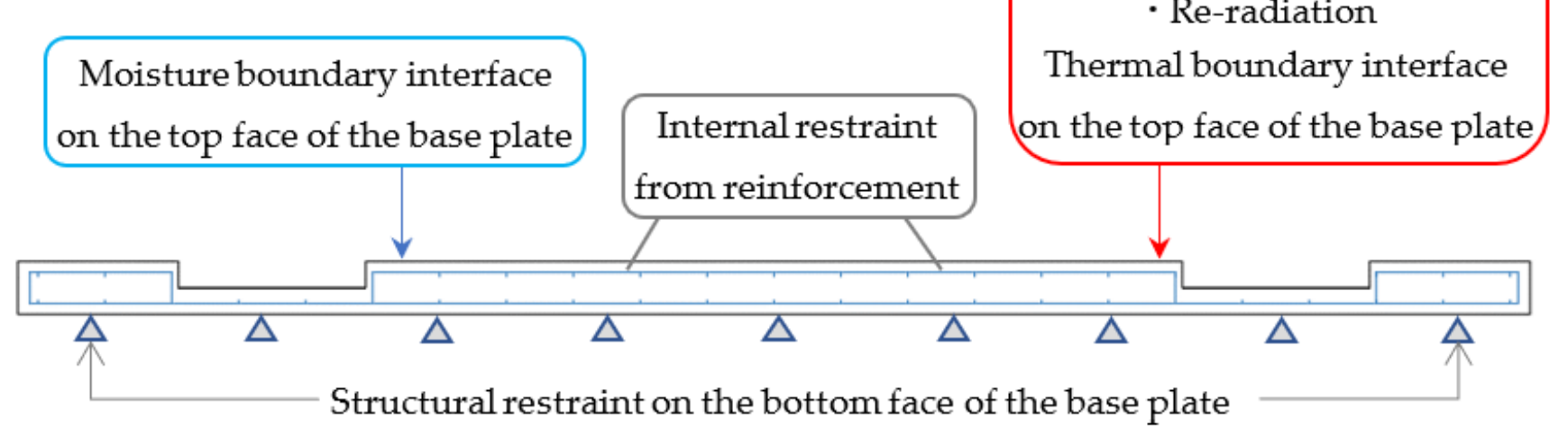

- Heat conduction

- Solar radiation

- Re-radiation

Thermal boundary interface

the top face of the base plate

Figure 6. Boundary conditions of the CRTS III base plate.

The heat exchange between the concrete surface and air due to long wave re-radiation is calculated by the following Stefan-Boltzmann equation:

$$
q_{r}=\varepsilon \sigma\left(T_{\text {sur }}^{4}-T_{\text {env }}^{4}\right)
$$

where $\sigma$ is the Stefan-Boltzmann constant $\left(5.669 \times 10^{-8} \cdot \mathrm{W} \cdot \mathrm{m}^{-2} \cdot \mathrm{K}^{-4}\right)$, and $\varepsilon$ represents the emissivity of concrete (0.85).

In order to simplify the calculation, re-radiation could be accounted for together with convection via a single radiation-convection coefficient, $\beta_{c r}=\beta_{c}+\beta_{r}$, where the following is the case [27].

$$
\beta_{r}= \begin{cases}\varepsilon\left[4.8+0.0075\left(T_{\text {sur }}-278.15\right)\right], & T_{\text {sur }} \geq 278.15 \mathrm{~K} \\ 4.8 \varepsilon, & T_{\text {sur }}<278.15 \mathrm{~K}\end{cases}
$$

When temporary curing is adopted, an "equivalent heat transfer coefficient" $\beta_{\text {eq }}$ can be applied in Equation (6). The material layers between the concrete surface and the air can 
be observed as associated in series, and the equivalent convective coefficient is described as follows [27]:

$$
\beta_{e q}=\left(\frac{1}{\beta_{c r}}+\sum_{1}^{n} \frac{d_{i}}{k_{i}}\right)^{-1}
$$

where $d_{i}$ is the thickness, and $k_{i}$ is the convective coefficient of each ith layer.

Heat transfer from short-wave solar radiation (SR) to concrete can be computed as follows:

$$
q_{s}=\alpha_{s} I_{n}(1-\gamma)
$$

where $\alpha_{s}$ is the absorptivity of concrete surface (0.65); and $I_{n}$ is the direct SR intensity $\left(\mathrm{W} / \mathrm{m}^{2}\right)$, assumed to follow a sinusoidal function during the daytime. In this study, the data of the daily maximum $I_{n}$ were obtained from a public meteorological information website. $\gamma$ is the absorption efficiency factor that relies on cover materials and thicknesses.

When the heat flux equations in Equations (6), (7), and (10) are combined, the thermal boundary condition can be expressed as follows:

$$
\alpha_{s} I_{n}(1-\gamma)-\beta_{\text {eq }}\left(T_{\text {sur }}-T_{\text {air }}\right)+k_{T}\left(\frac{\partial T}{\partial n}\right)=0
$$

where $\partial T / \partial n$ is the temperature gradient in direction $n$ of the concrete surface.

In order to ensure realistic temperature filed simulation of the base plate, the temperature field of the girder was also included in the thermal analysis. Heat flux at the top boundary of the FE model shown in Figure 5 consisted of combined heat flow from convection, solar radiation, and re-radiation. With respect to the lateral and bottom boundaries of the FE model, heat flux was assumed to be affected only by convection (Figure 6).

For the moisture analysis, the boundary condition is described as follows:

$$
\lambda\left(H-H_{\text {env }}\right)+D(H) \frac{\partial H}{\partial n}=0
$$

where $\partial H / \partial n$ is the RH gradient in direction $n$ of the surface, and $H_{e n v}$ is the environment $\mathrm{RH}$. The average $\mathrm{RH}$ is taken as $45 \%$ based on historical weather data.

For structural analysis, "small sliding" contact was used to simulate the interface between the base plate and bridge foundation. The friction coefficient was chosen as 0.6. The self-weight of the base plate was considered as a gravity load in the analysis. The condition of symmetry was applied to the girder on the plane of symmetry. No external restraint was set to be preventing expansion and contraction of the girder in the longitudinal direction.

\subsection{Selection of Materiel Parameters}

The strength grade of the base plate concrete is C40 ( $28 \mathrm{~d}$ compressive strength). Thermal conductivity, specific heat capacity, and coefficient of thermal expansion (CTE) were needed for heat transfer analysis, which are listed in Table 3. The input parameters of base plate concrete for moisture diffusion analysis are listed in Table 4. For structural analysis, the aforementioned MPS creep model was adopted for describing the viscoelasticity of base plate concrete, and the parameters are shown in Table 5. Linear-elastic constitutive equations were used for the girder concrete and steel bars (Table 6). The creep and shrinkage behavior of the girder was out of consideration due to the fact that the field base plates were cast more than 800 days after the fabrication of the girder. A fixed elastic modulus of 45 GPa was selected for the girder concrete according to the measured result of resilient modulus by a resiliometer. 
Table 3. Material parameters of the FE model components for heat transfer analysis.

\begin{tabular}{|c|c|c|c|c|c|}
\hline Component & Material & $\begin{array}{c}\text { Coefficient of } \\
\text { Thermal Expansion } \\
\left({ }^{\circ} \mathbf{C}^{-1}\right)\end{array}$ & $\begin{array}{c}\text { Specific Heat } \\
\text { Capacity } \\
\left(\mathrm{J} \cdot \mathrm{kg}^{-1 .}{ }^{\circ} \mathrm{C}^{-1}\right)\end{array}$ & $\begin{array}{c}\text { Thermal } \\
\text { Conductivity } \\
\left(\mathrm{W} \cdot \mathrm{m}^{-1} \cdot{ }^{\circ} \mathrm{C}^{-1}\right)\end{array}$ & $\begin{array}{l}\text { Density } \\
\left(\mathrm{kg} / \mathrm{m}^{3}\right)\end{array}$ \\
\hline Base plate & concrete & $9.5 \times 10^{-6}$ & 980 & 2.45 & 2500 \\
\hline Steel bar & Steel & $11.8 \times 10^{-6}$ & 460 & 46.0 & 7800 \\
\hline Girder & concrete & $9.5 \times 10^{-6}$ & 950 & 2.28 & 2500 \\
\hline \multirow{2}{*}{$\begin{array}{l}\text { Surface transfer } \\
\text { coefficient } \\
\left(\mathrm{W} \cdot \mathrm{m}^{-2} \cdot{ }^{\circ} \mathrm{C}^{-1}\right)\end{array}$} & uncovered & \multicolumn{2}{|c|}{ covered by geotextile } & \multicolumn{2}{|c|}{ covered by geotextile and quilt } \\
\hline & 16.8 & \multicolumn{2}{|c|}{7.0} & \multicolumn{2}{|c|}{1.55} \\
\hline
\end{tabular}

Table 4. Material parameters of base plate concrete for moisture diffusion analysis.

\begin{tabular}{ccccccc}
\hline $\begin{array}{c}\boldsymbol{D}_{\mathbf{0}} \\
\left(\times \mathbf{1 0}^{-\mathbf{5}} /\left(\mathbf{m}^{\mathbf{2}} / \mathrm{d}\right)\right)\end{array}$ & $\alpha$ & $\boldsymbol{\beta}$ & $\boldsymbol{H}_{\mathrm{c}}$ & $\lambda\left(\mathbf{m}^{\mathbf{2}} / \mathrm{d}\right)$ & $p_{\mathbf{1}}$ & $p_{\mathbf{2}}$ \\
\hline 8.36 & 0.049 & 1.5 & 0.925 & 0.020 & 0.0035 & 6.1 \\
\hline
\end{tabular}

Table 5. Material parameters of base plate concrete for the MPS theory-based creep model.

\begin{tabular}{|c|c|c|c|c|c|c|}
\hline $\begin{array}{c}q_{1} \\
\left(\times 10^{-6} / \mathrm{MPa}\right)\end{array}$ & $\begin{array}{c}q_{2} \\
\left(\times 10^{-6} / \mathrm{MPa}\right)\end{array}$ & $\begin{array}{c}q_{3} \\
\left(\times 10^{-6} / \mathrm{MPa}\right)\end{array}$ & $\begin{array}{c}q_{4} \\
\left(\times 10^{-6} / \mathrm{MPa}\right)\end{array}$ & $\underset{\left(\times 10^{-14} / \mathrm{MPa}^{2} / \text { day }\right)}{C}$ & $a$ & $\begin{array}{c}k_{1} \\
(\mathrm{MPa} / \mathrm{K})\end{array}$ \\
\hline 32.5 & 41.6 & 21.5 & 24.3 & 7.2 & 1.0 & 2.5 \\
\hline
\end{tabular}

Table 6. Mechanical parameters of the FE model components.

\begin{tabular}{cccc}
\hline Component & Material & Elastic Modulus (GPa) & Poisson's Ratio \\
\hline Base plate & concrete & - & 0.2 \\
\hline Steel bar & Steel & 205 & 0.3 \\
\hline Girder & concrete & 50 & 0.2 \\
\hline
\end{tabular}

\section{Results and Discussion}

\subsection{Measured Temperature Profile and Temperature Gradient Frequency Distribution}

In railways, the maximum temperature gradient for track structure design references concrete pavement specifications. However, due to the large differences in dimension and environment boundary between the base plate and pavement, the data measured from pavement are not suitable for the base plate [33]. Many research investigations concentrate on thermo-mechanical analysis of the slab track but only in the operation stage and not in the construction stage $[34,35]$. Since it is well known that a large part of temperature gradient in concrete plate is nonlinear and can cause large inner stress within the concrete, this section focuses on the statistical distribution of temperature gradient in field base plates cured with different regimes.

As an example, Figure 7 presents the temperature distribution curves measured at the center of Plate I-a (covered by geotextile for 20 days) during a $24 \mathrm{~h}$ cycle from 12 November 2020 to 13 November 2020, 3 days after casting. It is clearly observed that the temperature measured at the top portion of the base plate had larger daily changes than the temperature at the bottom portion. Therefore, the temperature gradient along the depth in the top portion of the base plate was more pronounced than that in the bottom portion. In the current design specifications for CRTS track system, the nonlinear temperature gradient is ignored. Nevertheless, this section aims to assess the influences of environmental boundary conditions on the overall temperature gradient and not the characteristic of nonlinearity. 


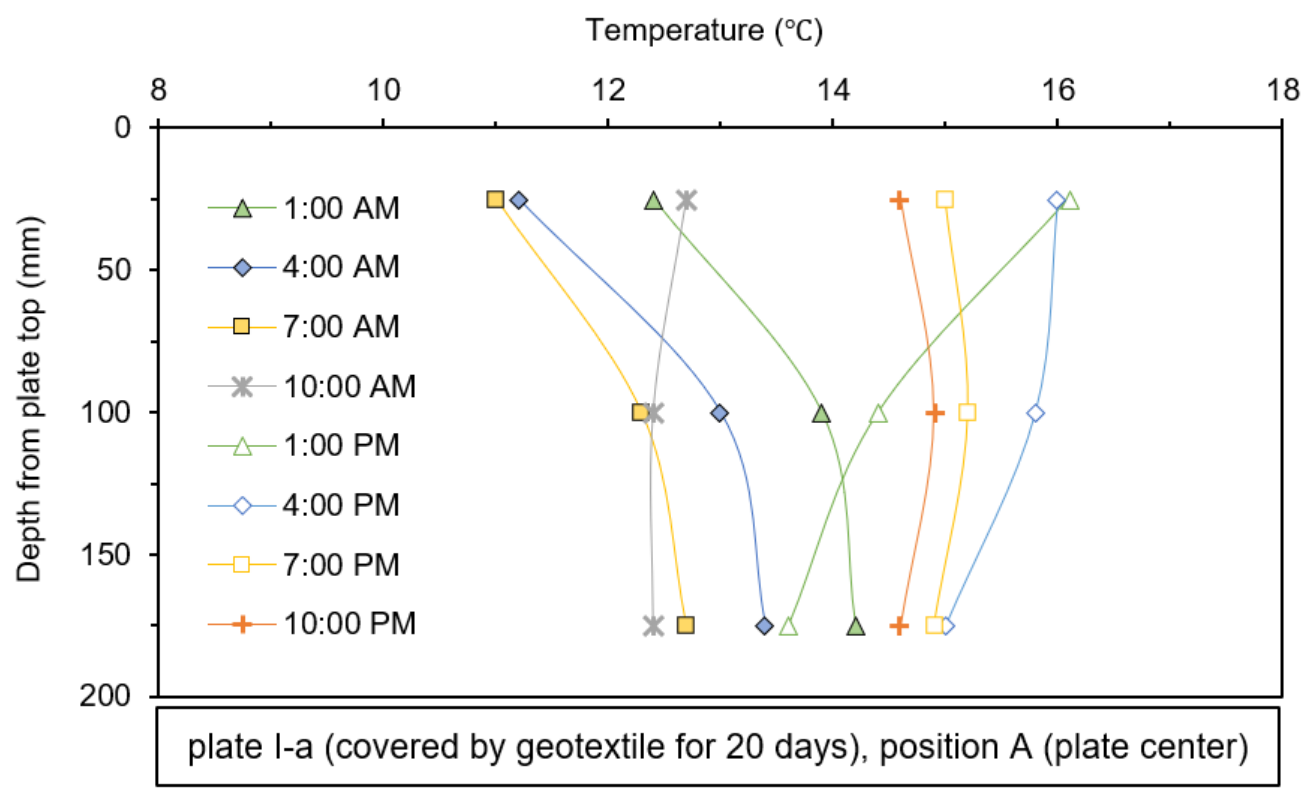

Figure 7. Measured temperature in Plate I-a during a $24 \mathrm{~h}$ cycle (from 12 December 2020 to 13 December 2020, 3 days after concrete placement).

By using the acquired temperature data from the three VWSGs in plate center/edge regions, the vertical temperature gradient can be calculated by using the following formula:

$$
T_{g}=\left(T_{\text {top }}-T_{\text {bottom }}\right) /\left(H_{\text {top }}-H_{\text {bottom }}\right)
$$

where $T_{g}$ is the vertical temperature gradient $\left({ }^{\circ} \mathrm{C} / \mathrm{m}\right),-T_{\text {top }}$ and $T_{\text {bottom }}$ are temperatures measured by two sensors at the top and bottom layers $\left({ }^{\circ} \mathrm{C}\right)$, and $H_{\text {top }}=0.175 \mathrm{~m}$ and $H_{\text {bottom }}=0.025 \mathrm{~m}$ are the heights of the sensors.

A frequency account analysis was carried out by using the hourly temperature gradient data from placement to the age of 150 days calculated by Equation (13). Figure 8 presents the comparison of temperature gradient frequency distributions in base plates under different curing conditions (Figure $8 \mathrm{a}$ for plate center and Figure $8 \mathrm{~b}$ for plate edge). In general, the temperature gradient at the plate center was larger than that at the plate edge. This is attributed to only one direction of heat exchange with the air at the plate center, while two directions were attributed at the edge. Thus, the edge of the base plate had a narrower temperature gradient distribution compared to the center. As observed from Figure $8 \mathrm{a}$, the temperature gradient at the plate center ranged from -30 to $45^{\circ} \mathrm{C} / \mathrm{m}$, indicating that the absolute values of night time temperature gradients were not as extreme as the daytime gradients. For Series I, II, III, and IV, the most frequently occurring temperature gradient was around $-9.0,-7.5,-3.5$, and $-3.0^{\circ} \mathrm{C} / \mathrm{m}$, respectively. Negative temperature gradients were indicated to be more frequent in the tested days (in winter and spring). The absolute value of the most frequently temperature gradient is in a descending order from Series I, II, III to IV. 

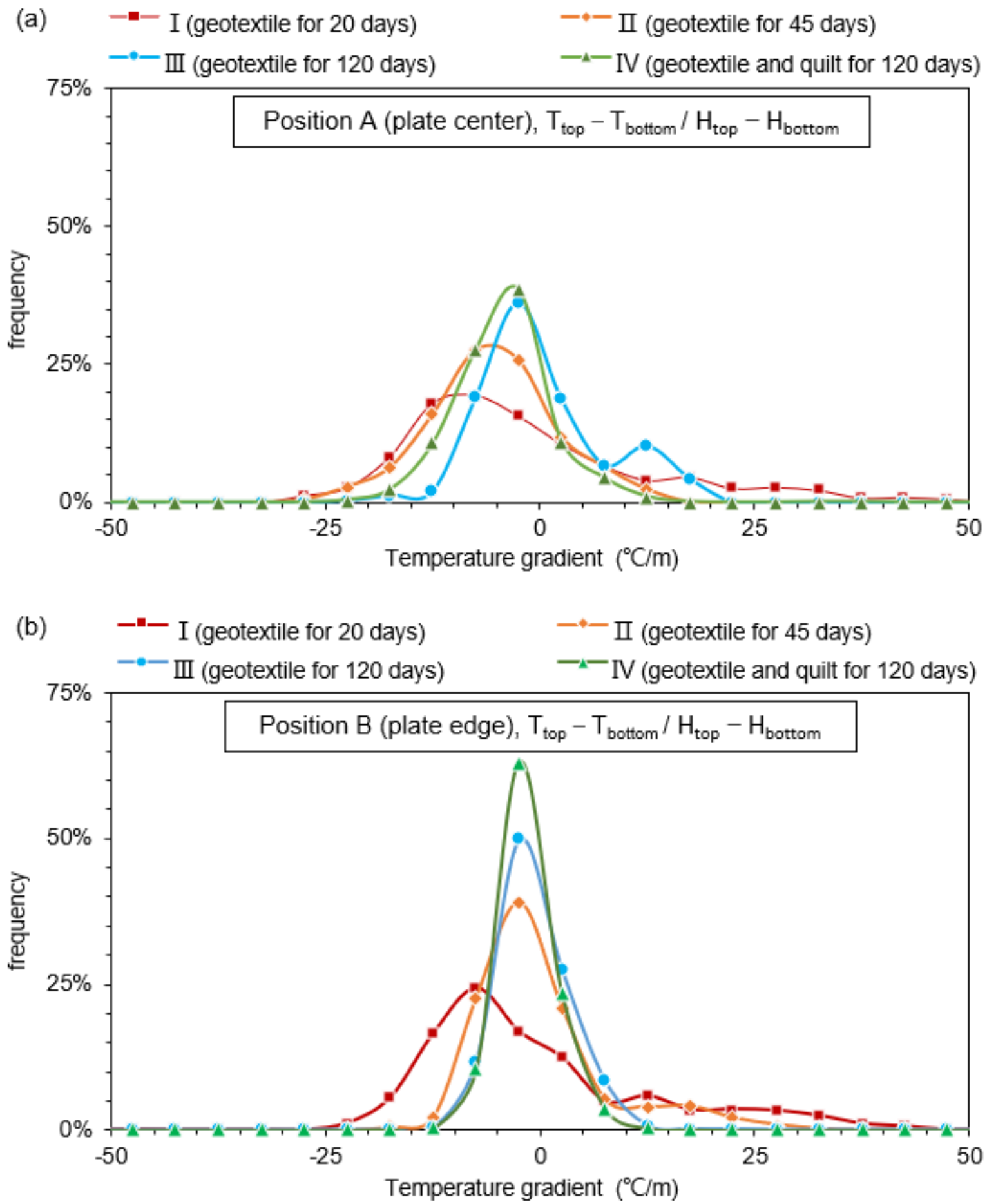

Figure 8. Comparison of temperature gradient frequency distributions in base plates under different curing conditions: (a) Position A (plate center); (b) Position B (plate edge).

The percentages of different levels of temperature gradient are shown in Table 7 . The most frequent temperature gradient level was from -10 to $0{ }^{\circ} \mathrm{C} / \mathrm{m}$ at $34.9 \%$ for Series I; $53.4 \%$ for Series II; $55.3 \%$ for Series III; and $66.5 \%$ for Series IV. The second frequently occurring temperature gradient level was from 0 to $10^{\circ} \mathrm{C} / \mathrm{m}$, with the percentages of $17.2 \%$, $18.4 \%, 25.5 \%$, and $18.7 \%$ for Series I, II, III, and IV, respectively. For Series III and IV, more than $80 \%$ of the gradient was between -10 and $10^{\circ} \mathrm{C} / \mathrm{m}$ during the tested days. As for Series I and II, only $52.0 \%$ and $71.8 \%$ periods in the gradient level from -10 to $10{ }^{\circ} \mathrm{C} / \mathrm{m}$ 
were observed due to the earlier exposure of these base plates to the environment. These results revealed the evident influence of curing conditions on temperature gradients.

Table 7. Percentage of different levels of temperature gradient measured from filed base plates.

\begin{tabular}{cccccccc}
\hline \multirow{2}{*}{$\begin{array}{c}\text { Test } \\
\text { Series }\end{array}$} & \multirow{2}{*}{ Position } & \multicolumn{5}{c}{ Level of Temperature Gradient $\left({ }^{\circ} \mathbf{C} / \mathbf{m}\right)$} \\
\cline { 3 - 7 } & & $\mathbf{- 4 5}$ to $-\mathbf{2 0}$ & $-\mathbf{2 0}$ to $-\mathbf{1 0}$ & $\mathbf{- 1 0}$ to $\mathbf{0}$ & $\mathbf{0}$ to $\mathbf{1 0}$ & $\mathbf{1 0}$ to $\mathbf{2 0}$ & $\mathbf{2 0}$ to $\mathbf{4 5}$ \\
\hline \multirow{2}{*}{ I } & A (center) & $3.9 \%$ & $25.8 \%$ & $34.9 \%$ & $17.2 \%$ & $8.5 \%$ & $9.8 \%$ \\
& B (edge) & $1.3 \%$ & $20.4 \%$ & $41.1 \%$ & $17.3 \%$ & $9.2 \%$ & $10.8 \%$ \\
II & A (center) & $3.4 \%$ & $22.3 \%$ & $53.4 \%$ & $18.4 \%$ & $2.5 \%$ & $0.0 \%$ \\
& B (edge) & $0.0 \%$ & $2.6 \%$ & $60.3 \%$ & $26.1 \%$ & $8.1 \%$ & $3.3 \%$ \\
III & A (center) & $0.3 \%$ & $4.5 \%$ & $55.3 \%$ & $25.5 \%$ & $14.5 \%$ & $0.0 \%$ \\
& B (edge) & $0.0 \%$ & $0.3 \%$ & $62.8 \%$ & $35.9 \%$ & $0.8 \%$ & $0.1 \%$ \\
IV & A (center) & $0.5 \%$ & $13.0 \%$ & $66.5 \%$ & $18.7 \%$ & $1.1 \%$ & $0.3 \%$ \\
& B (edge) & $0.0 \%$ & $0.5 \%$ & $72.6 \%$ & $26.5 \%$ & $0.5 \%$ & $0.0 \%$ \\
\hline
\end{tabular}

From Figure 8 and Table 7, we can remarkably observe that the maximum temperature gradient, either at the plate center or at the edge, was in an increasing order from Series IV, III, and II to I. The maximal positive gradient and the minimal negative gradient of Series I were clearly higher than those of the other test series during the same test seasons. Therefore, the use of geotextile or quilts as a thermal-protective cover can lower the temperature gradient of the base plate and is expected to decrease related stresses.

\subsection{Measured Strain Development and Strain Rate-Based Cracking Monitoring}

Figure 9 shows the comparison of concrete strains measured at positions A-top (plate center), B-top (center of long edge), C-top (center of short edge), and D-top (corner) in the four series of field-instrumented concrete base plates cured with different regimes. Positive and negative strain values represent expansion and shrinkage, respectively. The initial expansion strain recorded during the first 14-day wet-curing period was attributed to swelling of surface concrete. It is observed from Figure 9a that after the 20 day long curing period, the measured concrete strains at positions C-top (center of short edge) and D-top (corner) of Plate I-a showed obvious decreasing trends over time because of concrete drying shrinkage and relatively weak restraints of the boundary conditions at these positions. In contrast, with respect to C-top (center of short edge) and D-top (corner), A-top (plate center) and B-top (center of long edge) exhibited much lower variations of strain with respect to the daily temperature cycles due to large structural constraints at the mid-length region. Consequently, large tensile stress can be induced in the mid-plate cross section of base plate.

Generally, a suddenly increase in measured concrete strain can be used as a criterion for identifying crack occurrence, i.e., crack opening. However, this happens only if the crack is extended right across the strain gauge. On the other hand, an unusual decrease in measured strain, whether suddenly or gradually, may also indicate the occurrence of a crack near the measuring position. For the latter case, the explanation could be that the cracking phenomenon at the crack-formed position affects the surrounding area; stress is relieved at the crack, and the self-restraint becomes weak thereafter. Thus, theoretically, the time of cracking at each monitoring position can be deduced from the in-site strain measurement. For example, a sharp increase in measured strain could be observed at A-top (center) of Plate III-a (Figure 9c) and B-top (center of long edge) of Plate IV-a (Figure 9d) only several days after the 120 days long curing, which means that cracks appeared and passed through the strain gauges. There was another case where a progressive decrease in measured concrete strain was observed at Positions A-top and B-top of Plate II-a (Figure 9b), which indicated that cracks appeared near the strain gauge.

From Figure 9a, it is observed that the measured strain at A-top and B-top of Plate I-a showed very large fluctuations with the daily temperature cycles after the 20 days long curing stage. The upward tendency of the measured strain was the result of continuous switching between crack opening and partial closure of the crack opening. In such cases, it is not easy to directly determine the exact time of cracking through the measured strain 
curve. A more precise and reliable determination of the time of cracking can be achieved based on the measured result of strain rate, which will be described later.

(a)<smiles>C=[14C][13CH]=[13CH]</smiles>

B-top (edge)

C-top (edge)

D-top (corner)

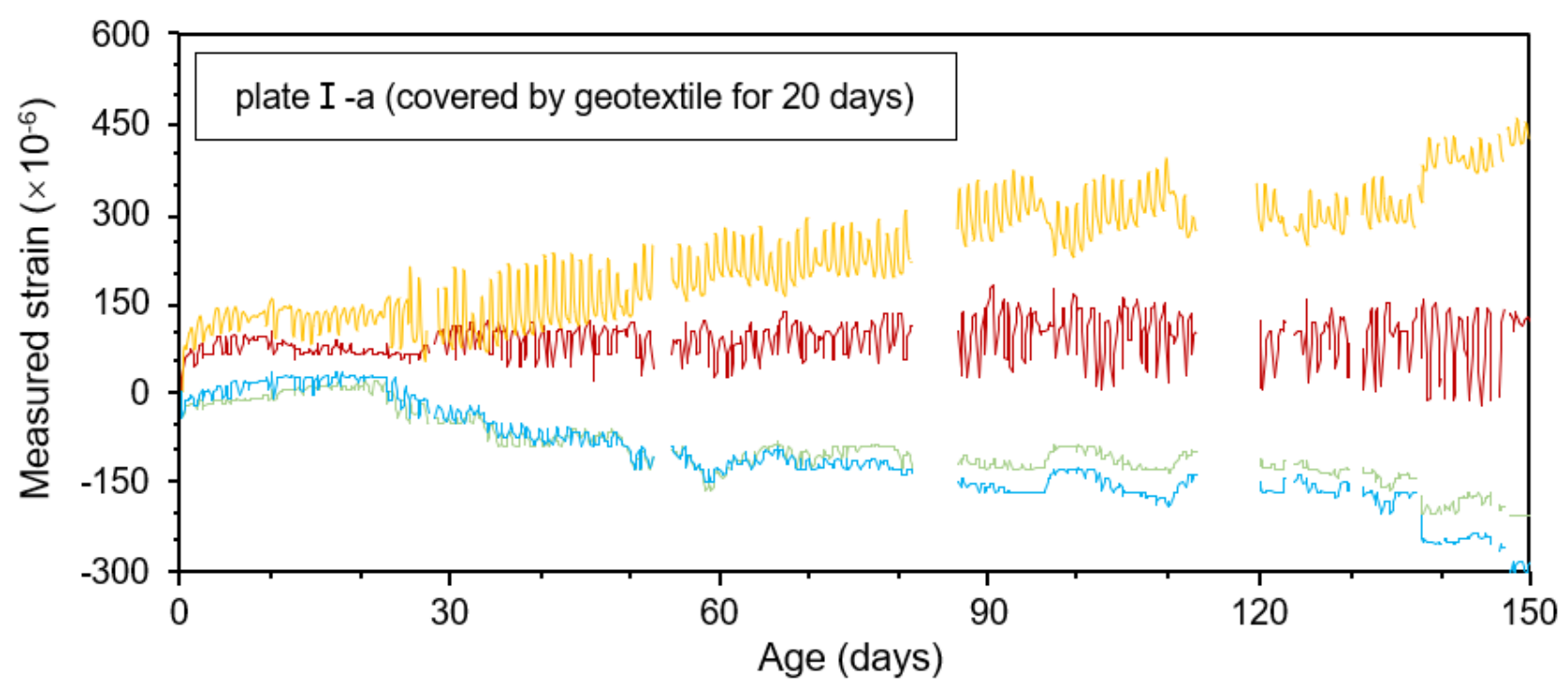

(b) A-top (center)

B-top (edge)

C-top (edge) D-top (corner)

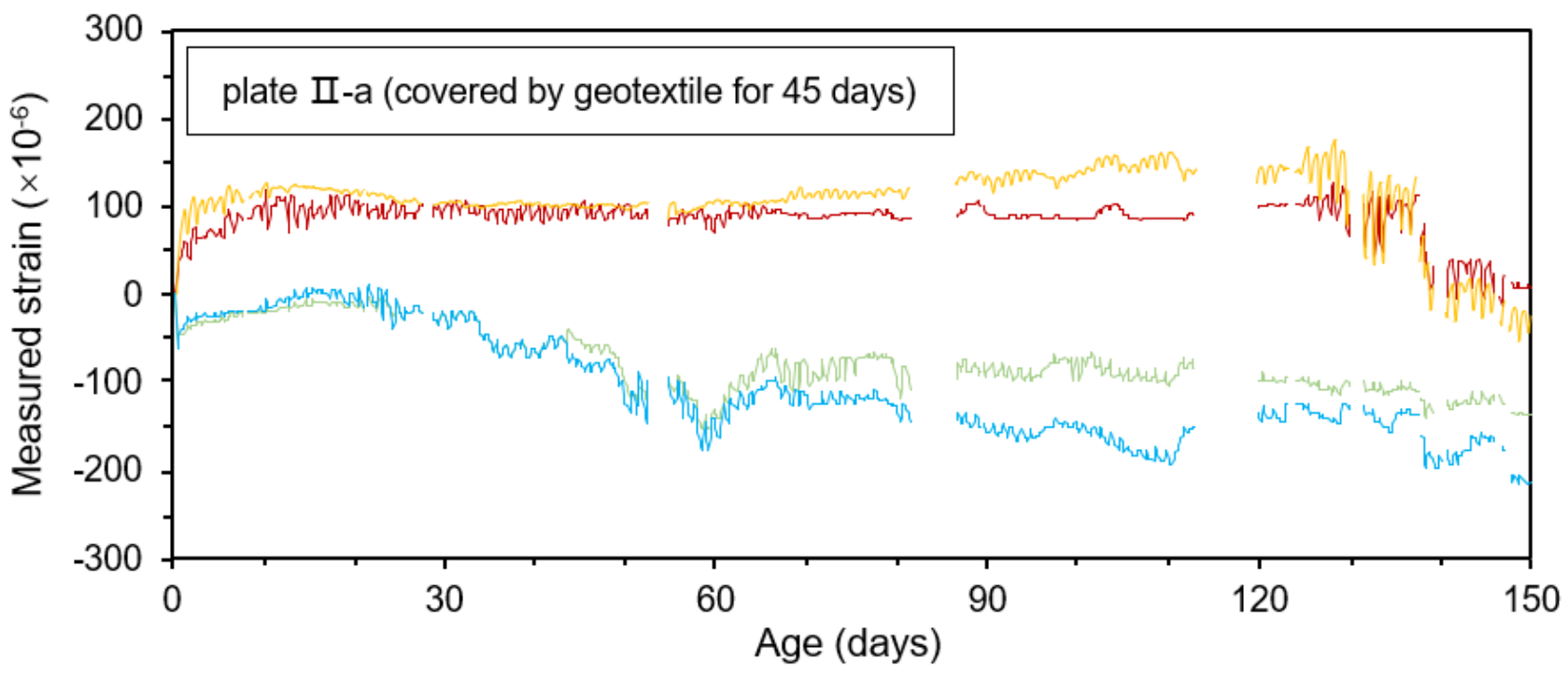

Figure 9. Cont. 
(c) A-top (center)

B-top (edge)

C-top (edge) D-top (corner)

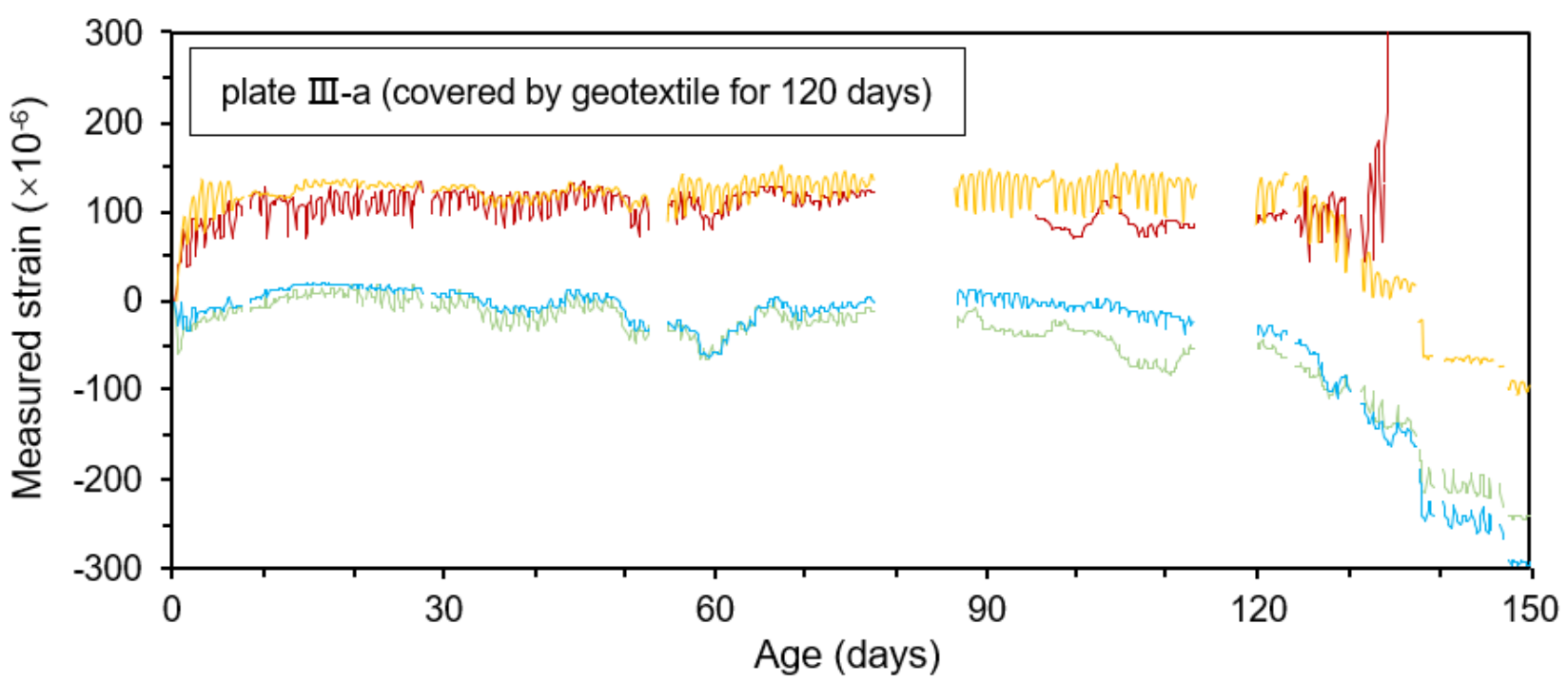

(d) B-top (edge) C-top (edge) D-top (corner)

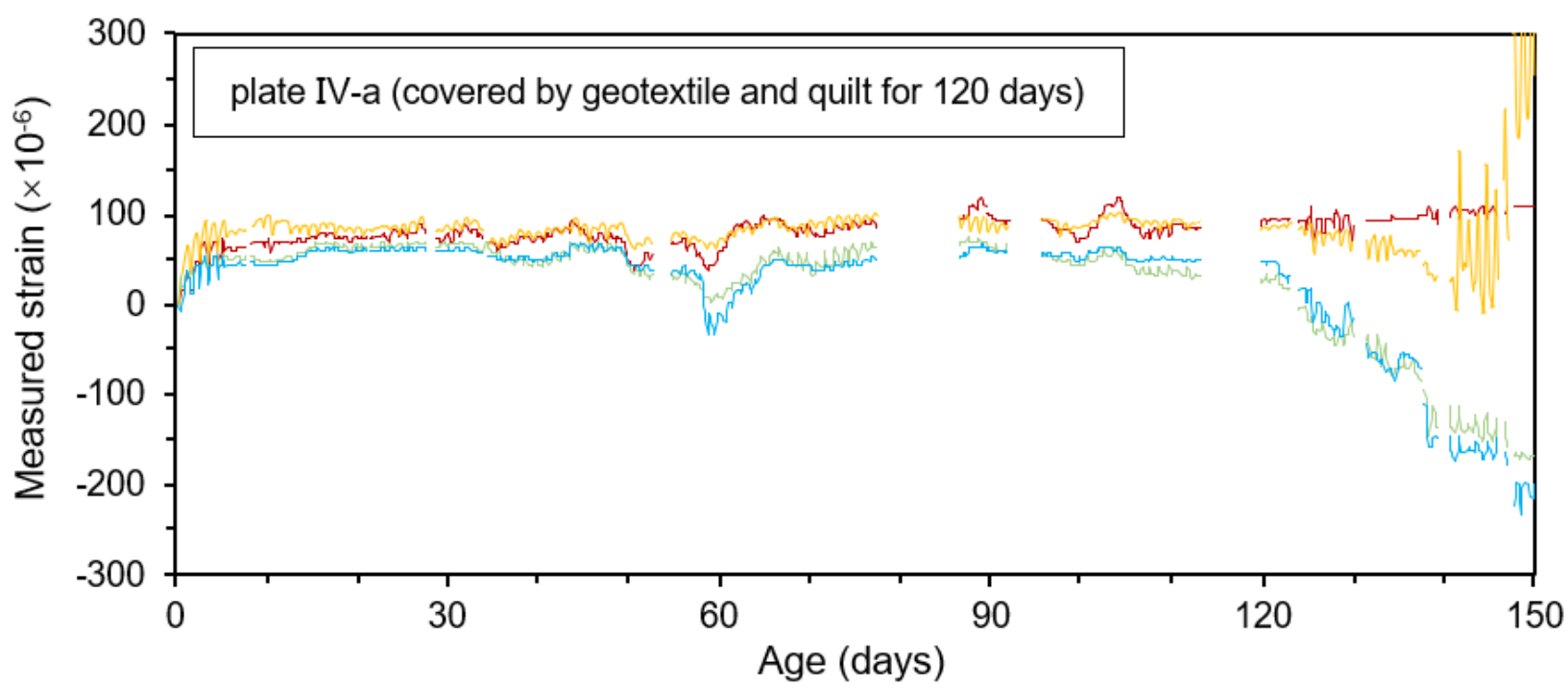

Figure 9. Comparison of measured strains at different positions in four test series of base plates with different curing regimes: (a) plate I-a, (b) plate II-a, (c) plate III-a, and (d) plate IV-a.

Figure 10a shows the variations of measured temperature and strain at the center (Position A) of Plate I-a during the 7 days after placement. It is observed that the measured temperature fluctuated due to the variations of air temperature and solar radiation. At early ages, the base plate experienced different combinations of temperature gradient, shrinkage, and swelling. The strain measured at the top layer was always larger than those measured at the middle and bottom layer during each temperature cycle (Figure 10b). As far as the author is concerned, two reasons contribute to this result. One is that the surface concrete swelled under wet-curing conditions. The other is that the plate top was subjected to lower external restraints compared with the middle and bottom portions. Figure 10c shows the measured strain rate at different depths (top, middle, and bottom) during 7 days after placement. The strain rate clearly showed positive and negative variations over time, and the varied amplitude of the strain rate decreased with the distance to the plate top surface.

Figure 11 shows the measured strain rate at different plate depths at Position A (plate center, Figure 11a) and Position B (center of long edge, Figure 11b) of Plate I-a. The first 
peak in the strain rate curve indicates the monitoring position started cracking, and the follow-up peaks reflect the sharp change of the measured strain produced by the existence of cracks. As inferred from Figure 11a, a crack occurred at A-top (plate center) on the 28th day after placement (8 days after exposed to drying). This crack did not extend into the full depth of the base plate because the strain rate peaks measured at A-middle and A-bottom did not increase significantly over time. From Figure 11b, it is deduced that a crack occurred at B-top on the 25th day after placement. As demonstrated in Figure 11, it is easy to track crack occurrence with the curves of strain rate. By this method, the initial time of cracking at each monitoring position was identified from the field strain rate data, and the results are summarized in Figure 12 and Table 8. As shown, the earlier the base plate was exposed to drying, the earlier cracks appeared. The initial cracking time is closely related to the duration of sealed-curing, although it is unlikely that early drying stress alone caused cracking.

It is a remarkable fact that the time of cracking detected at the plate edge was obviously earlier than that at the center, or perhaps no crack was detected at the plate center (Figure 12). For the two base plates of Series I (covered by geotextile for 20 days), the average time of cracking at plate edge (Position B) was 30 days, while the average time of cracking at plate center (Position A) was 35 days. For Series II (covered by geotextile for 45 days), the time of cracking at plate edge was 65 days for Plate II-a, and no crack was detected in Plate II-b. For Series III (covered by geotextile for 120 days), the time of cracking at plate edge was 56 days (before being exposed to drying) for Plate II-a, and it was 129 days for Plate II-b. The results between Plate II-a and Plate II-b were scattered, possibly because the presence of the strain gauge and cable caused earlier cracking in Plate II-a. For Series IV (covered by geotextile and quilt for 120 days), no crack was detected except for the edge (Position B) of Plate IV-a.

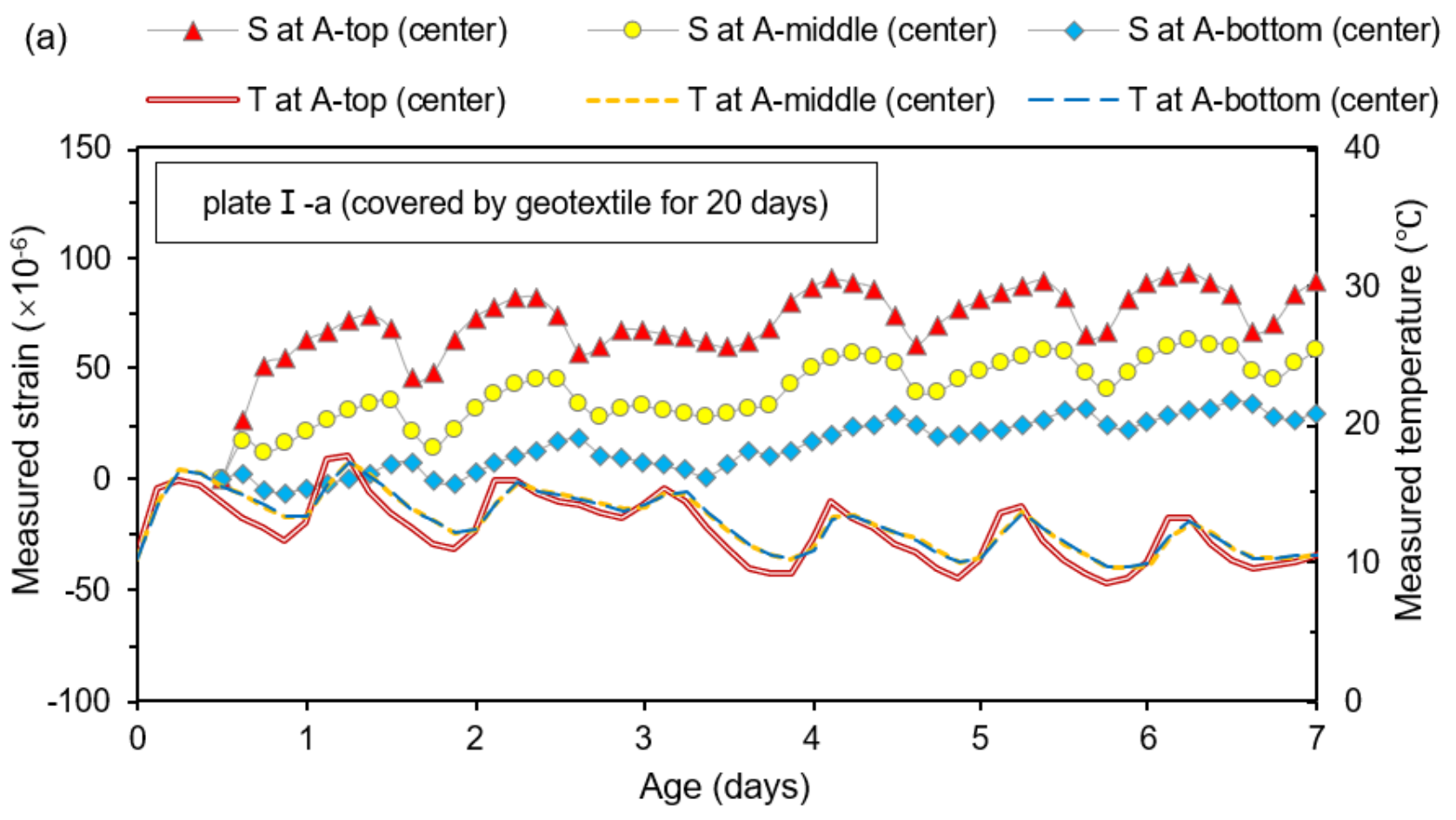

Figure 10. Cont. 
(b) Measured strain $\left(\times 10^{-6}\right)$

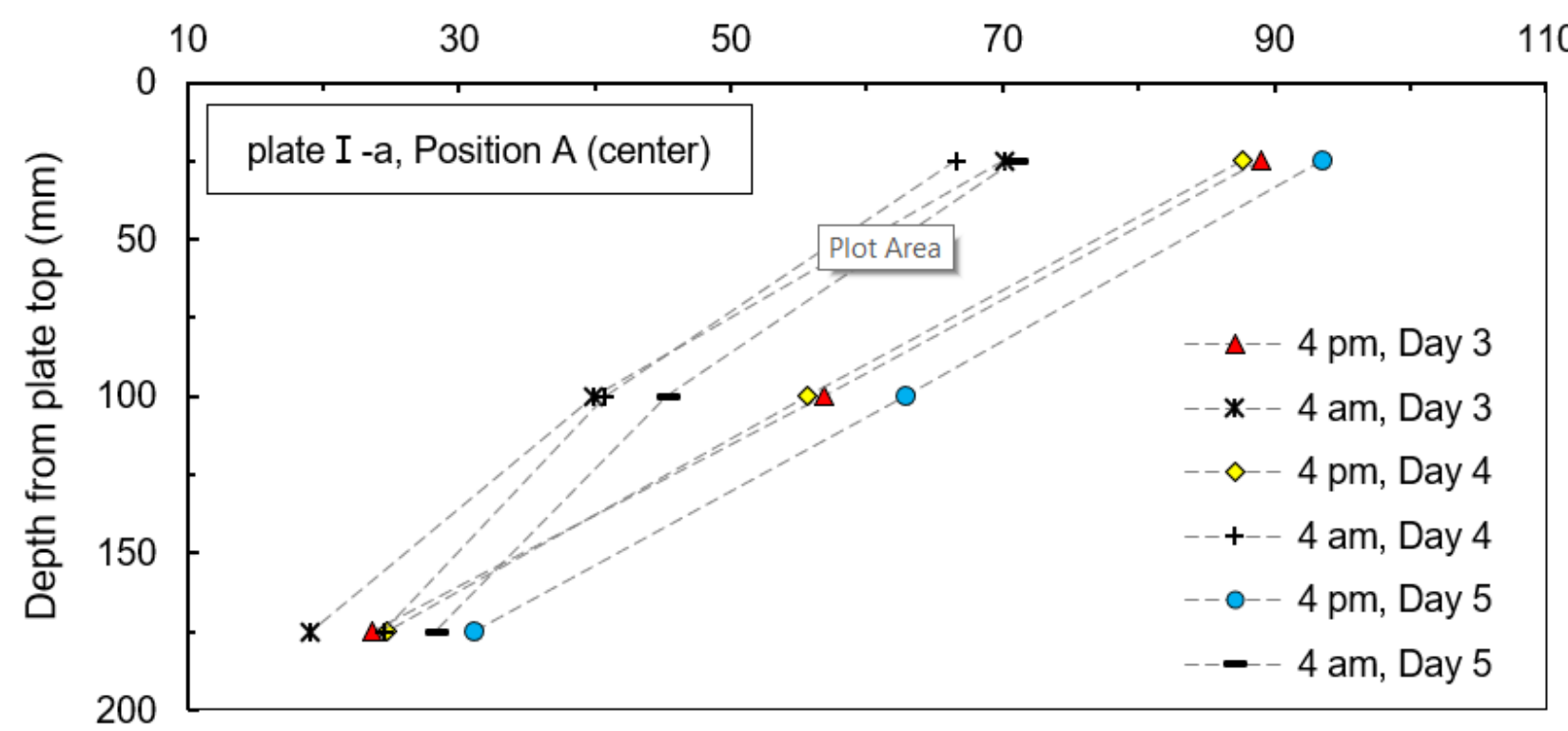

(c) $\longrightarrow$ SR at A-top (center) $\multimap-\mathrm{SR}$ at A-middle (center) $\multimap$ SR at A-bottom (center)

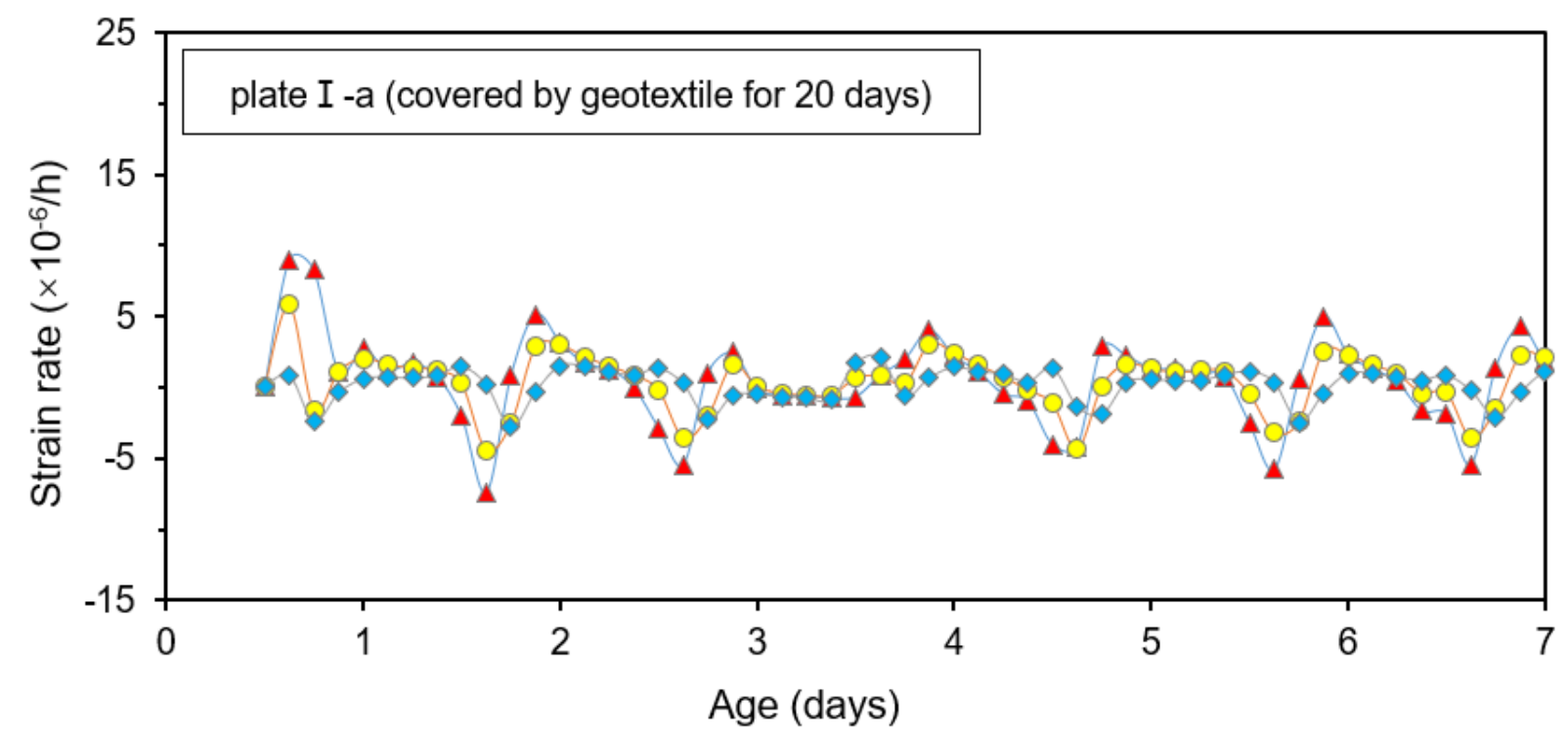

Figure 10. (a) Measured temperature and strain at the center of Plate I-a. (b) Measured strain distribution along the depth during day 3 to 5. (c) Measured strain rate at the plate center.

Table 8. Cracking time at positions A (plate center) and B (plate edge) deduced from in-site strain rate monitoring (as illustrated in Figure 11).

\begin{tabular}{cccccccccc}
\hline & \multicolumn{10}{c}{ Test Series } \\
\cline { 2 - 9 } Position & \multicolumn{2}{c}{ Series I } & \multicolumn{2}{c}{ Series II } & \multicolumn{2}{c}{ Series III } & \multicolumn{2}{c}{ Series IV } \\
\cline { 2 - 10 } & I-a & I-b & II-a & II-b & III-a & III-b & IV-a & IV-b \\
\hline A (center) & 28 & 42 & - & - & 125 & 136 & - & - \\
\hline B (edge) & 25 & 35 & 65 & - & 56 & 129 & 141 & - \\
\hline
\end{tabular}


(a) $\quad \ldots$ SR at A-top (center) $\cdots \quad$ SR at A-middle (center) $\cdots \quad$ SR at A-bottom (center)

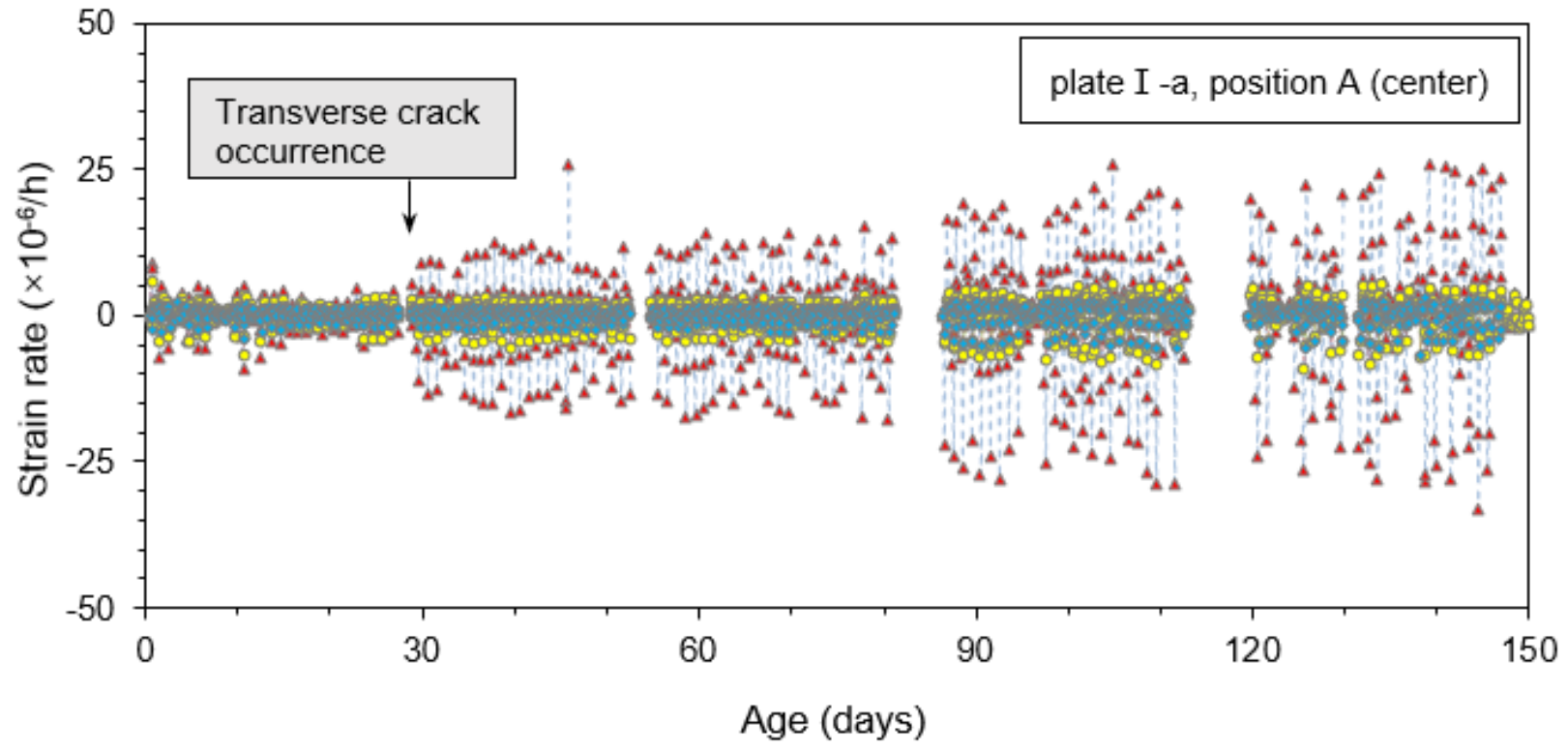

(b) $\quad$ SR at B-top (edge) $\cdots$ SR at B-middle (edge) $\cdots \quad$ SR at B-bottom (edge)

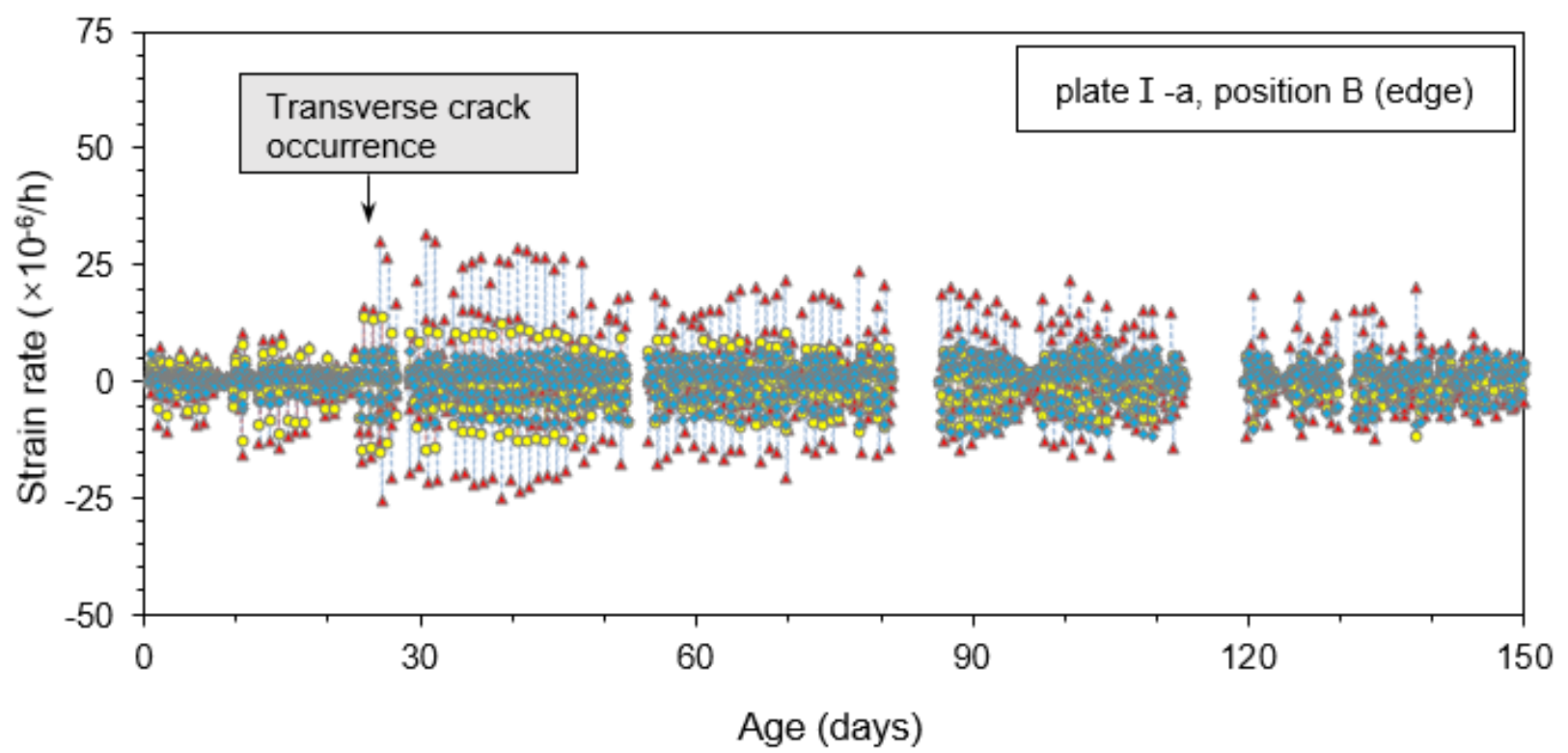

Figure 11. Measured strain rate at different depths of Plate I-a. (a) Position A (center); (b) Position B (plate). 


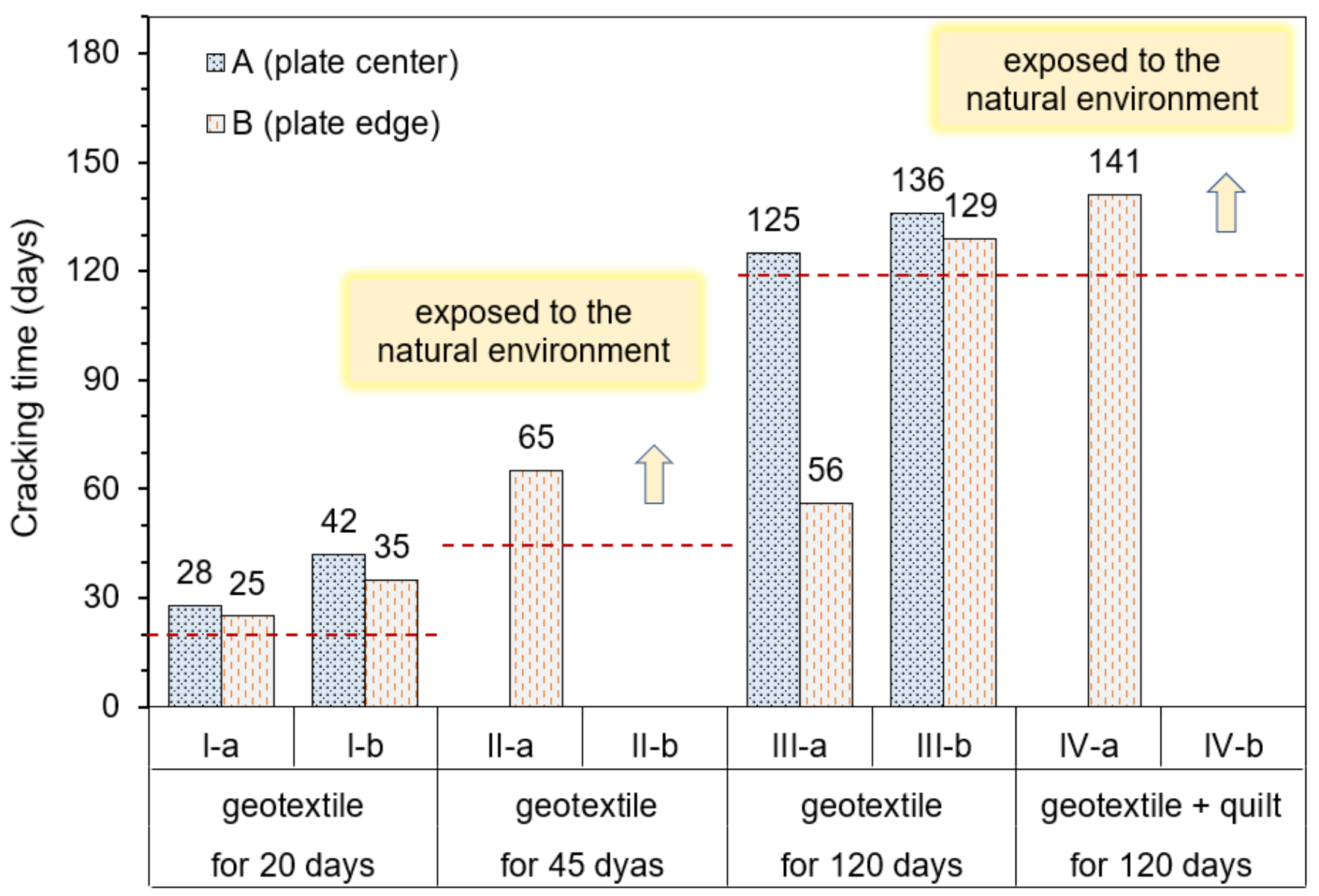

Figure 12. Initial cracking time at Positions A (plate center) and B (plate edge) deduced from the field measured strain rate curves (as illustrated in Figure 11).

\subsection{Crack Pattern from Field Inspection}

Field inspections are essential for checking the cracking positions on these base plates inferred from the monitoring strain rate. During the 150 days long field test, two field inspections were conducted at the ages of 65 and 130 days, respectively. Figure 13 shows the pattern of the visible cracks on the top surfaces of all the field base plates. Note that the blue lines represent the cracks found by the first inspection, and the red lines represent the cracks observed at the second inspection. In order to clarify crack propagation, the positions of the embedded VWSGs and the detected time of cracking at each position are also marked on the drawing from which it is easy to observe where and when the crack appeared. As observed from Figure 13, the development of transverse crack in all field base plates followed a similar mode. Regardless of the duration of sealed-curing period, a majority of transverse cracks were localized at the mid-length of the plate, i.e., the crack concentration region. However, the number of the transverse cracks significantly decreased with prolonged sealed curing time.

Clearly, transverse cracks originated from the plate edge on both sides of the plate and propagated toward the plate center. The easily incurred edge cracking, most likely located in the $2000 \mathrm{~mm}$ range in the middle area along the length, may be attributed to rapid drying at the edge and strong restraint of deformations in this area. It was observed from Plate I-a and Plate I-b that parallel short cracks formed alongside a from a main crack near the centerline, which were nearly uniformly spaced along the plate length. This finding reveals that although stress is relieved at a crack, cracking phenomenon affects the surrounding area only in a limited distance. Hence, transverse cracks can occur at close 
spacings. In contrast to Series I, Series II, III, and IV had a much better crack pattern, where the number of transverse cracks was less than two for each plate.

Series I-covered by geotex tile (20days)
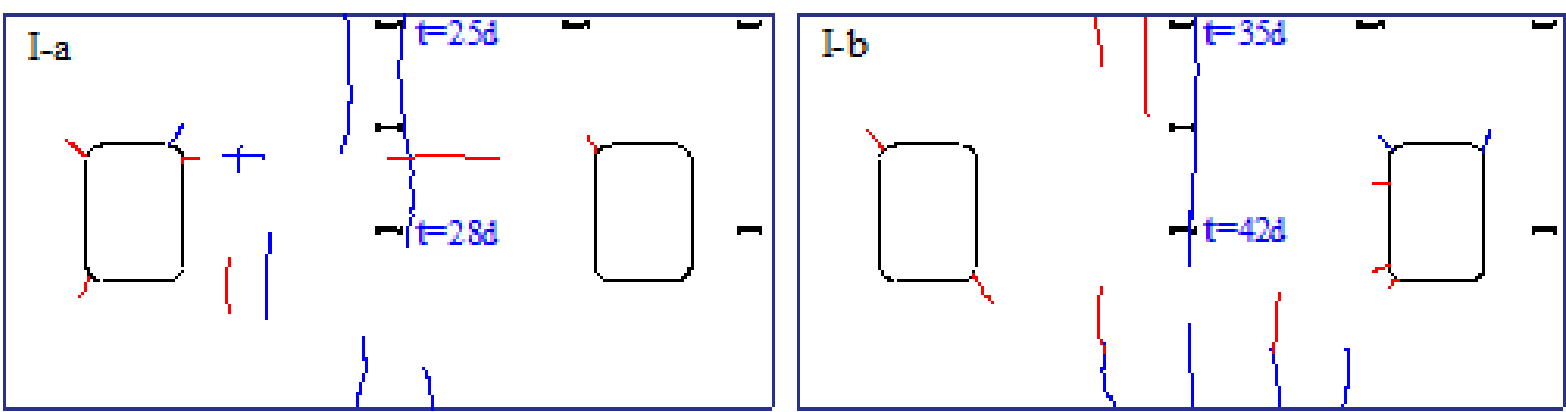

Series II-covered by geotex tile ( 45 days)

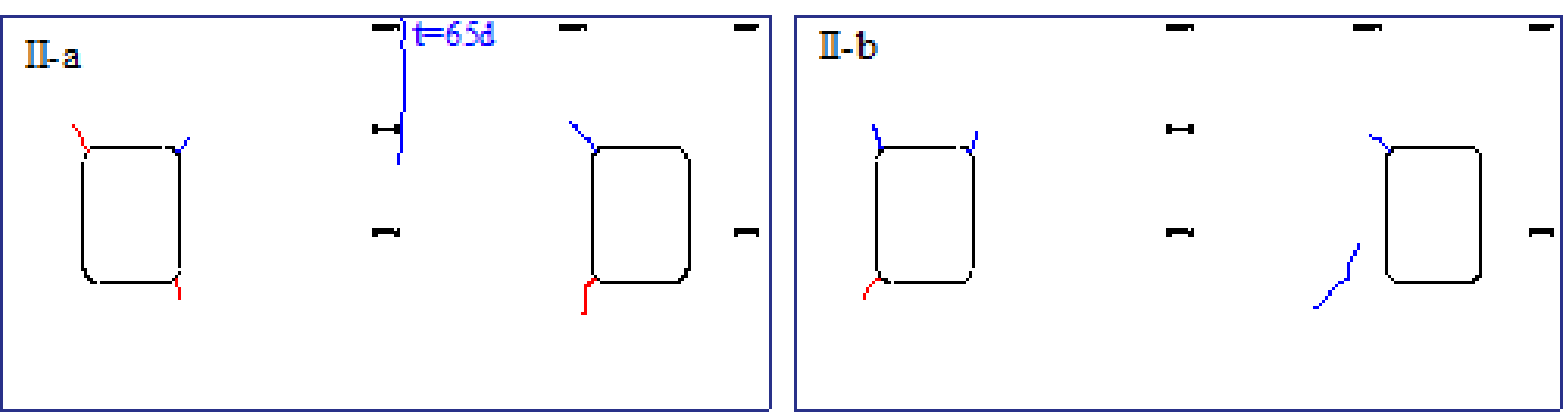

Series III-covered by geotextile (120days)

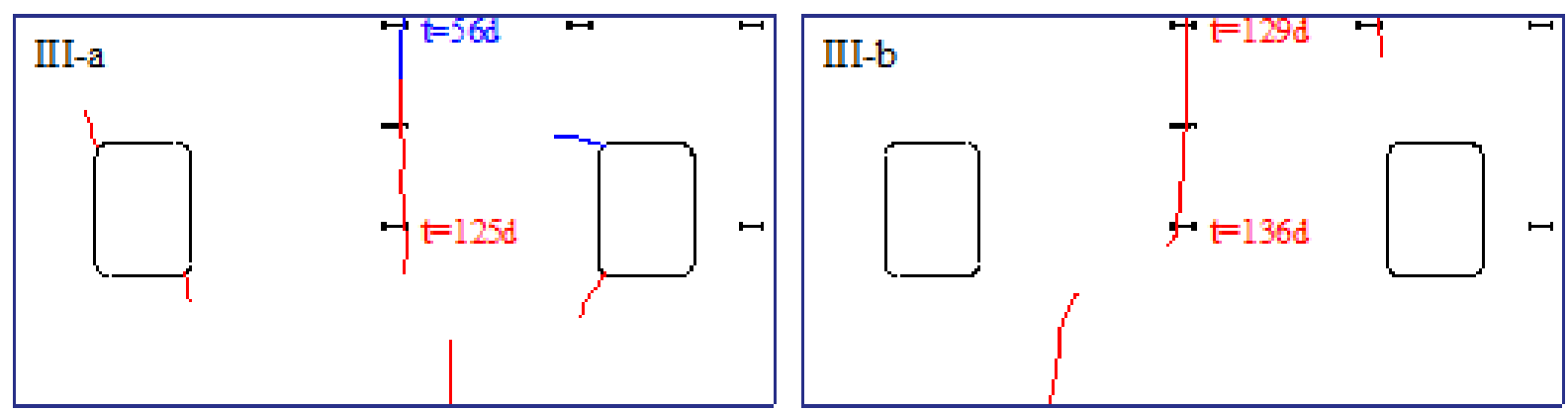

Series IV-covered by geotex tile and quilt (120days)

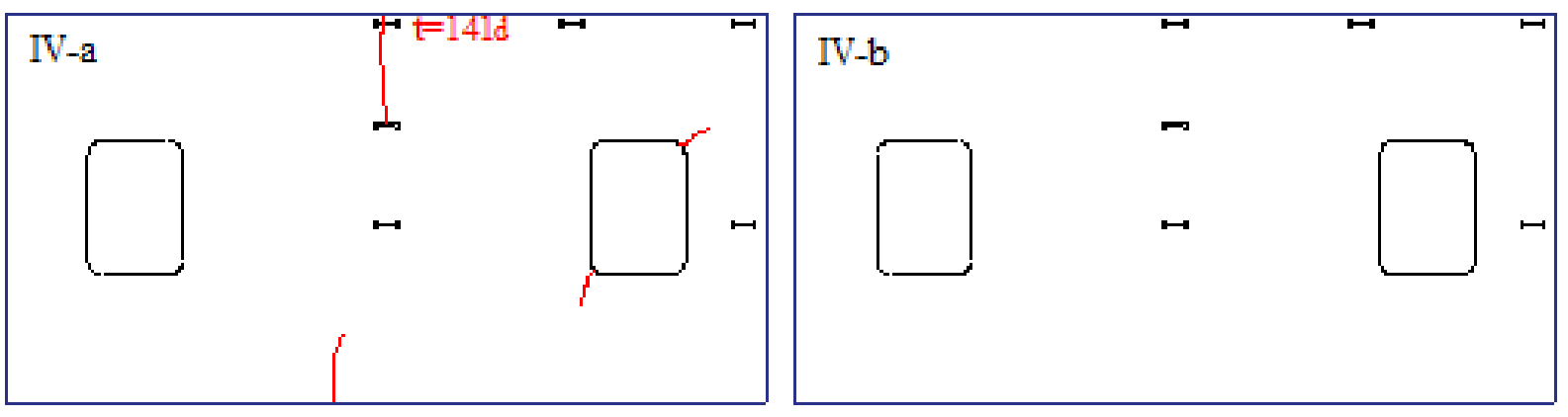

$\longmapsto$ vibrating wire strain gage

Figure 13. Crack patterns observed from field inspections. 


\subsection{Calculated Stress Development in Base Plates under Different Temperature and Humidity Boundary Conditions}

As discussed earlier, the different crack patterns on the four test series of base plates can be attributed to the different curing/environmental boundary conditions that existed during the test. In this section, the effects of various environmental boundary conditions on transverse crack initiation are numerically analyzed from the perspective of temperatureinduced and humidity-induced stresses. Since the transverse cracks are always initiated at the plate edge, it was taken as the region of interest in the analysis.

The temperature-induced stress simulation only considered the effect of the temperature field. Figure 14 shows the inputted historical data of air temperature and solar radiation for the temperature field simulation, which were obtained from a meteorological information website. The temperature-induced stresses of the different series of base plate were calculated with the same meteorological data, but the temperature boundary condition was altered according to the curing regime adopted for each series. Figure 15 shows the calculated temperature-induced longitudinal stresses at Edge-top (mid-length) and Edge-bottom (mid-length). The measured tensile strength of base plate concrete was also indicated in the figure, which was obtained by using a direct tension testing machine. As observed from Figure 15a,b, the geotextile covering effectively reduces not only the magnitude but also the amplitude of temperature-induced stress. After the geotextile cover was removed at 20 or 45 days, the temperature gradient in the base plate becomes larger and gives rise to the fluctuation of temperature stress. Compared with Series I and II, Series III and IV encountered a lower level temperature gradient before 120 days. Hence, the calculated temperature stresses at Points Edge-top and Edge-bottom are well below the tensile strength of concrete.

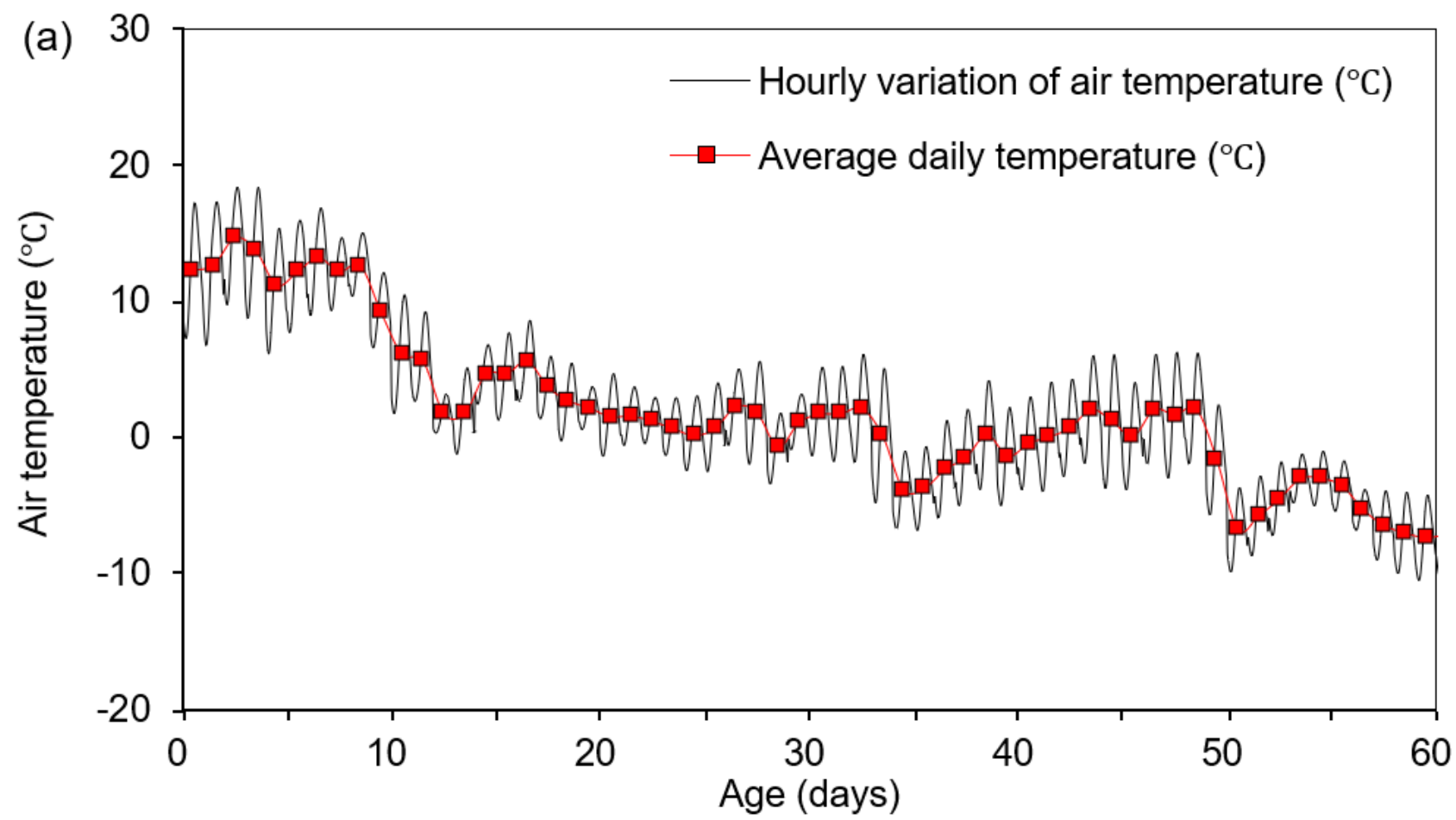

Figure 14. Cont. 


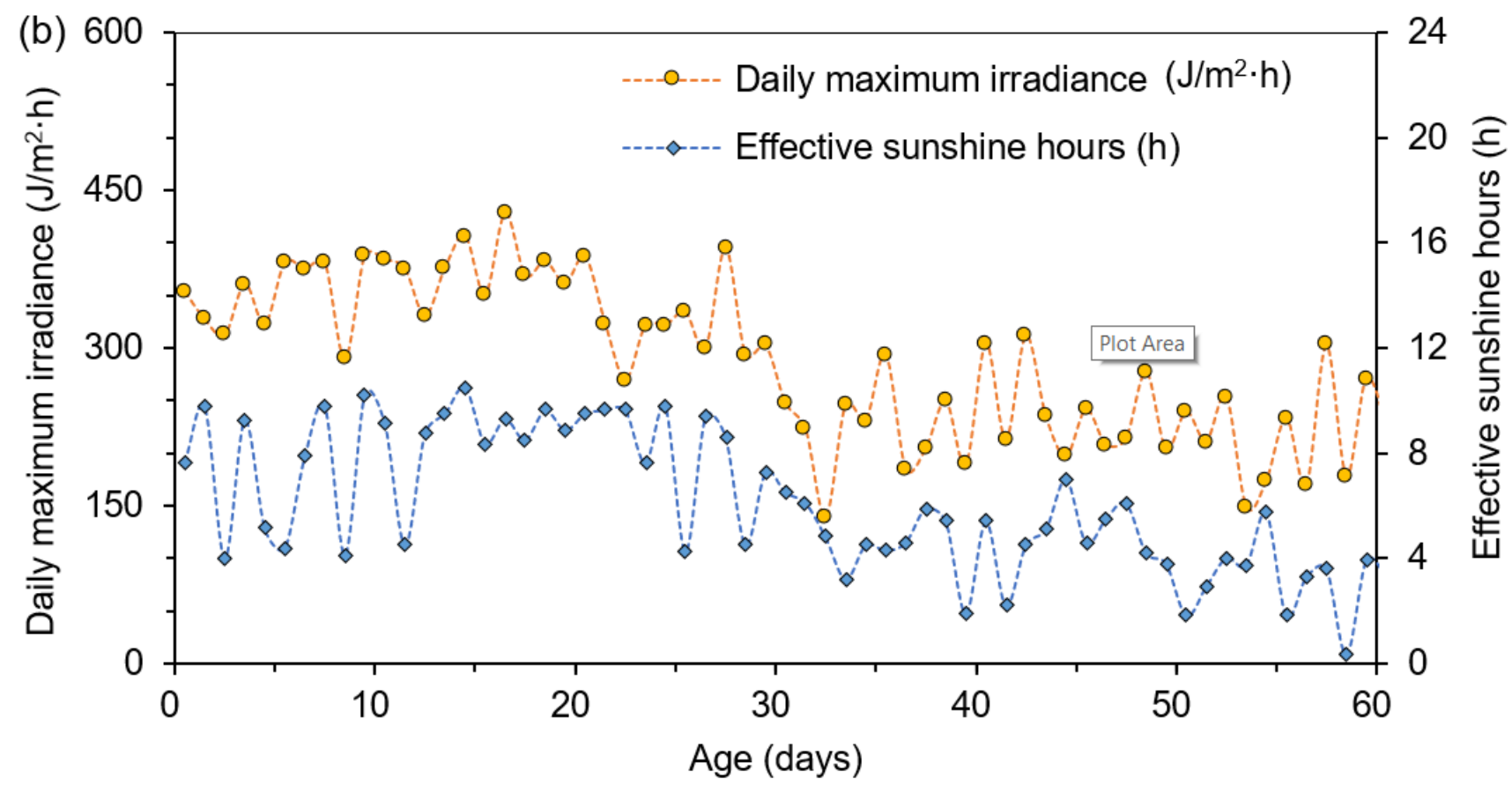

Figure 14. Inputted meteorological data for the temperature field analysis of field base plate. (a) Environmental temperature; (b) solar radiation.

(a) ------- Edge-top —— Edge-bottom - - - measured direct tensile strength

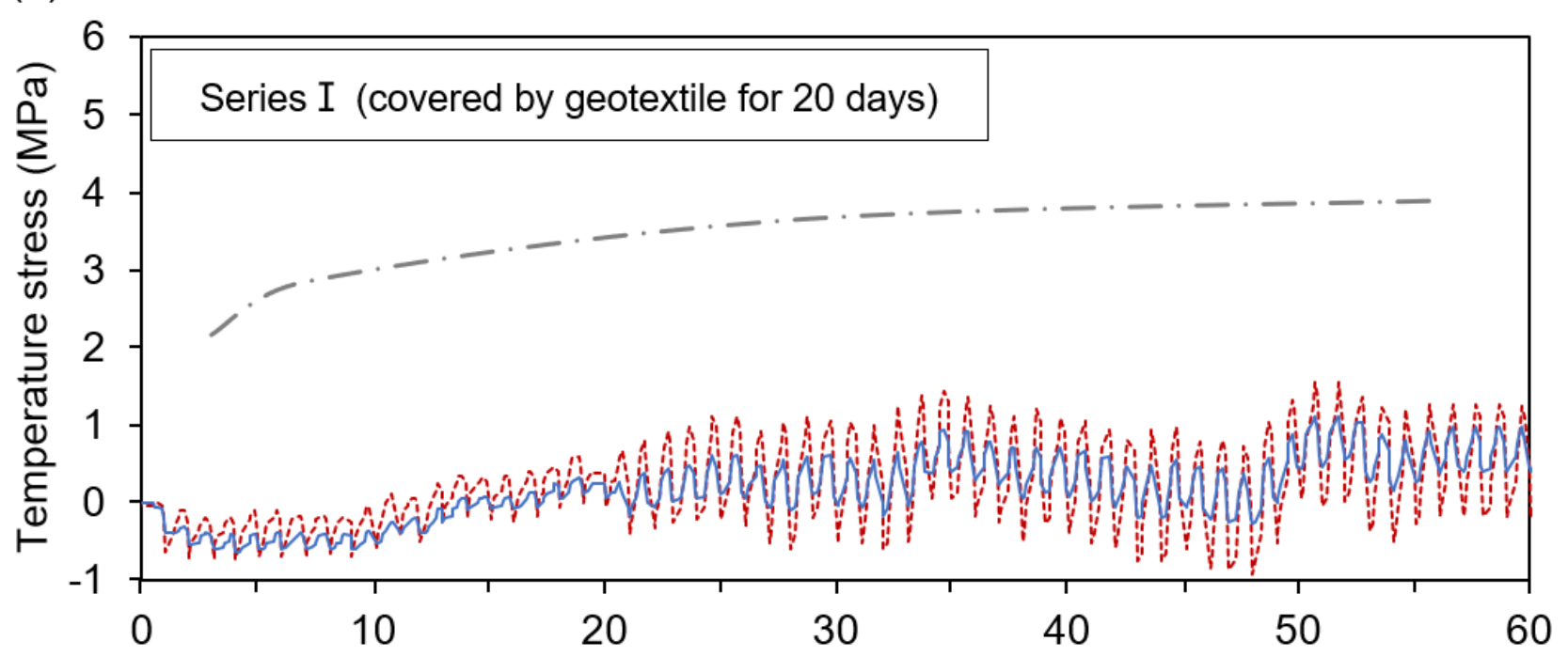

Figure 15. Cont. 

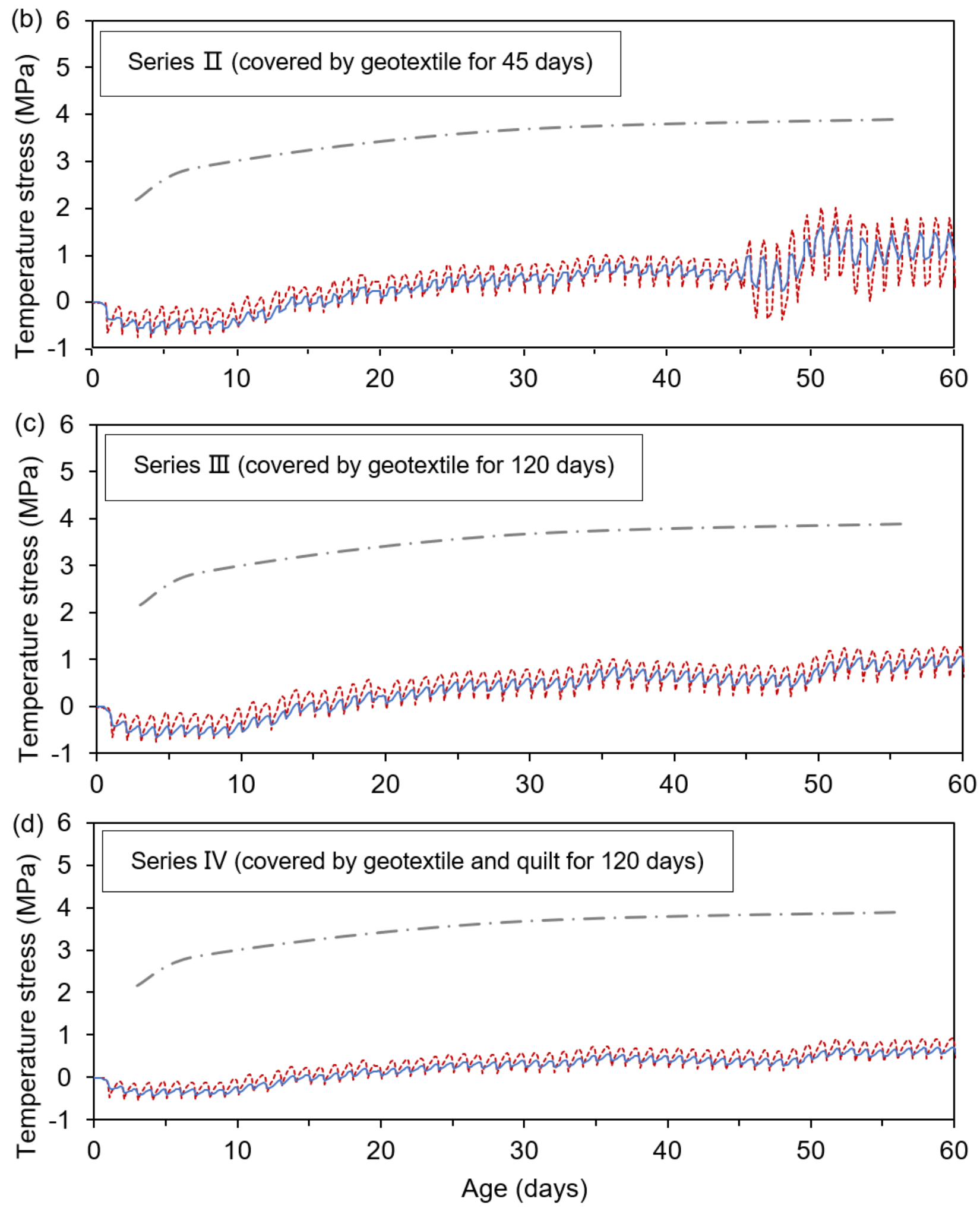

Figure 15. Calculated temperature-induced longitudinal stresses at positions Edge-top and Edge-bottom: (a) Series I, (b) Series II, (c) Series III, and (d) Series IV.

The humidity-induced stress simulation considered concrete strains of swelling and shrinkage. It was assumed that during the 14-day wet-curing, the top surface of the base plate was exposed to an $\mathrm{RH}$ of $100 \%$; during the sealed-curing period, no moisture exchange with the environment happened and only self-desiccation proceeded; after the 
geotextile cover was removed, the top and side surfaces of the base plate were exposed to an $\mathrm{RH}$ of $45 \%$. Figure 16 shows the calculated humidity-induced longitudinal stresses at Points Edge-top, Edge-middle, and Edge-bottom (mid-length). As shown, after the end of sealed curing, drying shrinkage stress develops very fast at Edge-top. It was observed that the prolonged seal-curing stage do not moderate drying shrinkage stresses. The reason lies in the fact that once exposed to external drying, a sharp drying front penetrates into the surface concrete. Steep humidity gradients arise at the exposed boundary, especially at Edge-top where two-direction drying occurs. Although the early-age creep effect has been fully considered in the stress analysis, the plate edge portion still reaches a large magnitude of self-induced shrinkage stress. This indicates that the surface layer of concrete is highly sensitive to cracking when exposed to the environment. This is in agreement with the conclusion reported by [36] that concrete cracking potential is closely related to the $\mathrm{RH}$ drop rate and shrinkage rate in the near-surface layer.
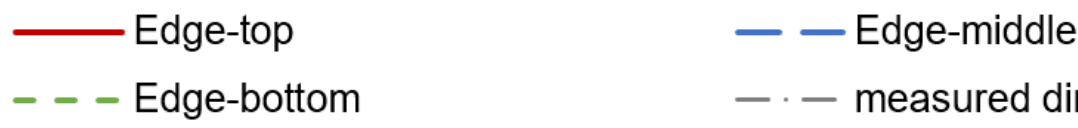

$-\cdot-$ measured direct tensile strength
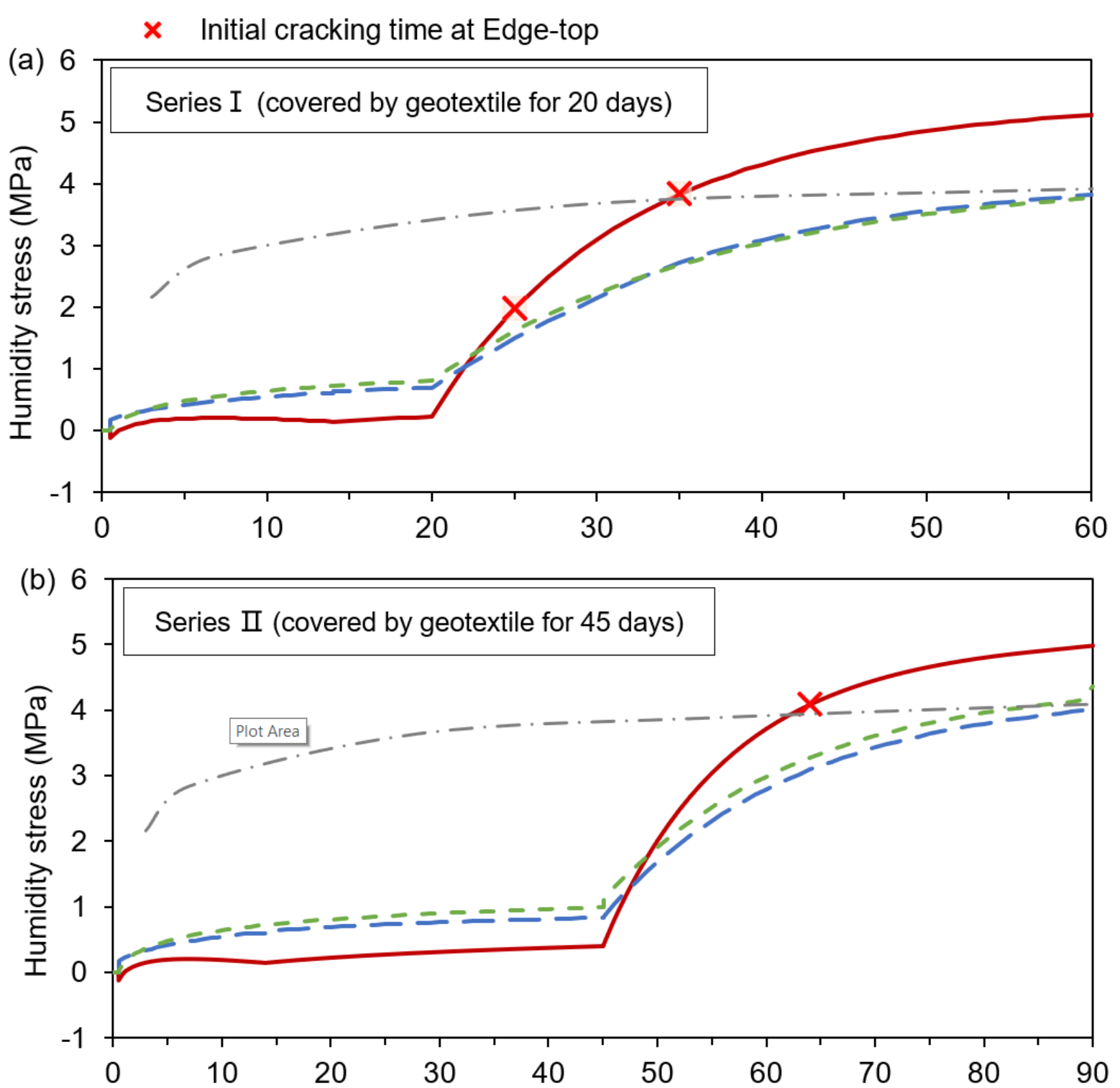

Figure 16. Cont. 


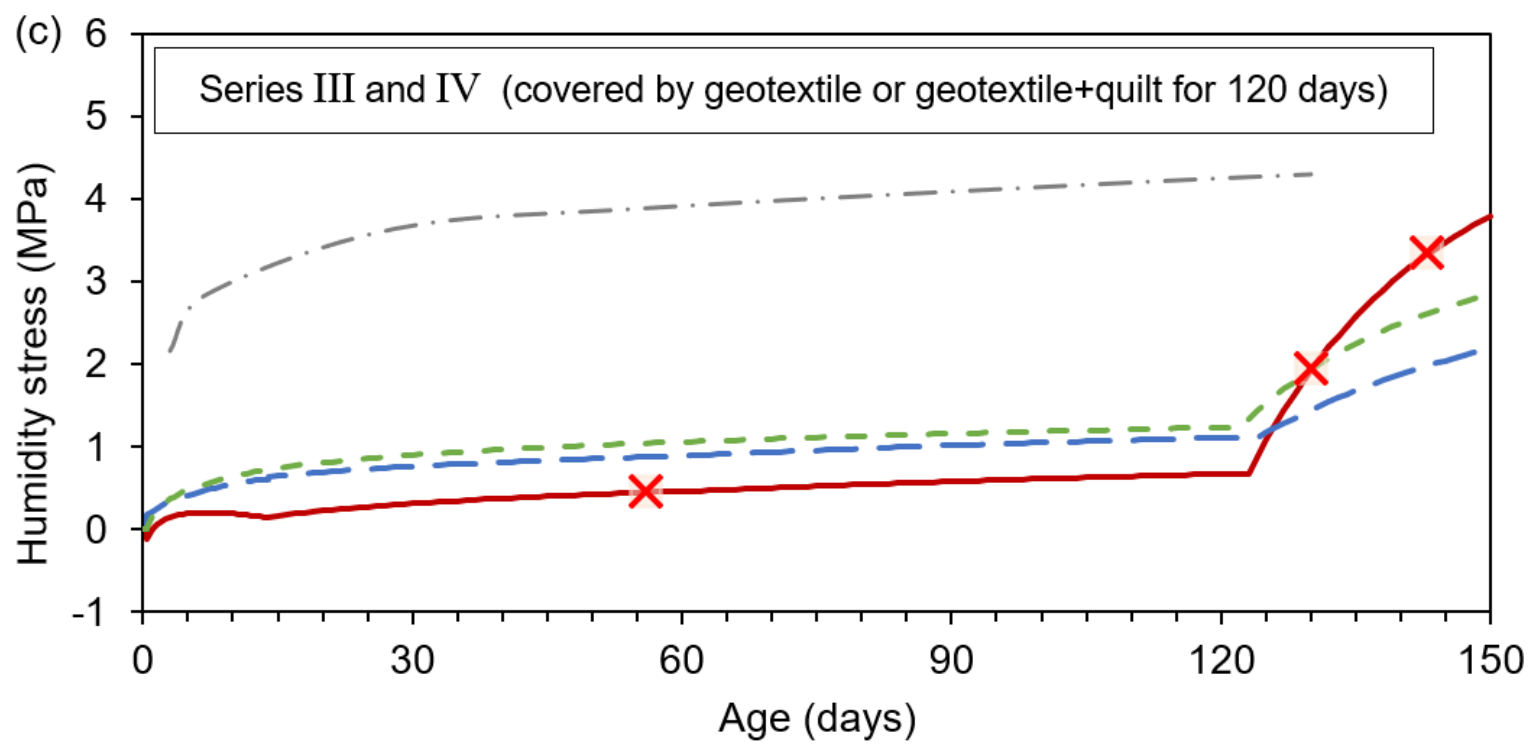

Figure 16. Calculated humidity-induced longitudinal stresses at positions Edge-top, Edge-middle, and Edge-bottom: (a) Series I, (b) Series II, and (c) Series III and IV.

For each curing regime, the calculated shrinkage stress at the time of plate edge cracking is much higher than the calculated temperature stress at the same time. Thus, the conclusion can be reached that drying induced stress is the leading cause of transverse cracks in the CRTS III base plate.

\section{Conclusions}

In this study, eight full-scale CRTS III concrete base plates were constructed, instrumented, and subjected to different curing regimes in order to investigate the effects of environmental boundary conditions on the early transverse cracking behavior of the base plate. In-situ variations of strain, temperature, and cracking of these concrete plates were monitored for 150 days. A numerical procedure was developed to simulate the temperatureinduced and humidity-induced stresses in these concrete base plates. The findings point to the following conclusions:

(1) Based on in-site strain monitoring made at the desired positions, the embedded strain gauges can provide an indication of when cracks occurred. A precise determination of the time of cracking in the field base plates can be achieved by monitoring the change of strain rate. The detected crack-occurred positions fit well with the positions of the cracks visually observed. Generally, transverse cracks originated from the plate edge on both sides of the plate and propagated toward the plate's center.

(2) Field inspections indicate that the early transverse cracks are quite susceptible to the curing conditions. A shorter sealed curing period will result in the earlier rise of transverse cracks and worse crack patterns. Inadequate curing will increase the number of cracks or, to be more specific, cause transverse cracks to occur at close spacings because a surface crack affects the surrounding area only at a limited distance.

(3) The numerical results indicate that drying induced stress is the leading cause of the transverse cracks in the CRTS III base plate, since the calculated shrinkage stress at the time of plate edge cracking is much larger than the calculated temperature stress at the same time. Extending sealed curing to 45 or 120 days can significantly reduce the number of cracks and delay the time to cracking but will not effectively moderate drying shrinkage stress. Therefore, in order to eliminate cracking tendency, curing compounds and long-term curing should be required in practical engineering. 
Author Contributions: Conceptualization, Y.W.; methodology, Y.W.; validation, W.G.; investigation, W.G., L.Z. and X.H.; resources, Y.W.; writing—original draft preparation, W.G.; writing-review and editing, Y.W.; visualization, L.Z. and X.H.; supervision, Y.W.; funding acquisition, Y.W. All authors have read and agreed to the published version of the manuscript.

Funding: This research was funded by National Natural Science Foundation of China (NSFC) under grant number of 52078273.

Institutional Review Board Statement: Not applicable.

Informed Consent Statement: Not applicable.

Data Availability Statement: Data is contained within the article.

Acknowledgments: The authors are thankful for the funding provided by the National Natural Science Foundation of China (NSFC) under grant number 52078273.

Conflicts of Interest: The authors declare that they have no conflict of interest.

\section{References}

1. Zeng, Z.P.; Huang, X.D.; Yan, B.; Wang, W.D.; Shuaibu, A.A.; He, X.F. Research on the fatigue performance of self-compacting concrete structure in CRTSIII slab ballastless track under the action of heavy haul train. Constr. Build. Mater. 2021, $303,124465$. [CrossRef]

2. Jiang, W.; Xie, Y.; Wu, J.; Guo, J.; Long, G. Identifying bonding interface flaws in CRTS III type ballastless track structure using the impact-echo method. Eng. Struct. 2021, 227, 111429. [CrossRef]

3. Liu, S.; Chen, X.; Ma, Y.; Yang, J.; Cai, D.; Yang, G. Modelling and in-situ measurement of dynamic behavior of asphalt supporting layer in slab track system. Constr. Build. Mater. 2019, 228, 116776. [CrossRef]

4. Chen, D.P. Multi-physicalfield coupling simulation of hygro-thermal deformation of concrete. J. Southeast Univ. Sci. 2013, 43, 582-587.

5. Ghatefar, A.; El-Salakawy, E.; Bassuoni, M.T. Early-age restrained shrinkage cracking of GFRP-RC bridge deck slabs: Effect of environmental conditions. Cem. Concr. Compos. 2015, 64, 62-73. [CrossRef]

6. $\quad$ Li, X.; Ren, J.; Wang, J.; Yang, R.; Shi, L.; Liu, X. Drying shrinkage of early-age concrete for twin-block slab track. Constr. Build. Mater. 2020, 243, 118237. [CrossRef]

7. Cortas, R.; Rozière, E.; Staquet, S.; Hamami, A.; Loukili, A.; Delplancke-Ogletree, M.P. Effect of the water saturation of aggregates on the shrinkage induced cracking risk of concrete at early age. Cem. Concr. Compos. 2014, 50, 1-9. [CrossRef]

8. Azenha, M.; Leitão, L.; Granja, J.L.; de Sousa, C.; Faria, R.; Barros, J.A. Experimental validation of a framework for hygromechanical simulation of self-induced stresses in concrete. Cem. Concr. Compos. 2017, 80, 41-54. [CrossRef]

9. Wei, Y.; Liang, S.; Gao, X. Numerical evaluation of moisture warping and stress in concrete pavement slabs with different water-to-cement ratio and thickness. J. Eng. Mech. 2017, 143, 04016111. [CrossRef]

10. Krauss, P.D.; Rogalla, E.A. Transverse Cracking in Newly Constructed Bridge Decks; NCHRP Report 380, Project 12-37; National Academy Press: Washington, DC, USA, 1996.

11. Choi, S.; Ha, S.; Won, M.C. Horizontal cracking of continuously reinforced concrete pavement under environmental loadings. Constr. Build. Mater. 2011, 25, 4250-4262. [CrossRef]

12. Sadati, S.S.; Cetin, K.; Ceylan, H.; Sassani, A.; Kim, S. Energy and thermal performance evaluation of an automated snow and ice removal system at airports using numerical modeling and field measurements. Sustain. Cities Soc. 2018, 43, 238-250. [CrossRef]

13. Song, L.; Liu, H.; Cui, C.; Yu, Z.; Li, Z. Thermal deformation and interfacial separation of a CRTS II slab ballastless track multilayer structure used in high-speed railways based on meteorological data. Constr. Build. Mater. 2020, 237, 117528. [CrossRef]

14. Xin, J.; Zhang, G.; Liu, Y.; Wang, Z.; Wu, Z. Effect of temperature history and restraint degree on cracking behavior of early-age concrete. Constr. Build. Mater. 2018, 192, 381-390. [CrossRef]

15. Aitcin, P.C. The durability characteristics of high-performance concrete: A review. Cem. Concr. Compos. 2003, 25, 409-420. [CrossRef]

16. Qian, S.Z.; Zhou, J.; Schlangen, E. Influence of curing condition and precracking time on the self-healing behavior of engineered cementitious composites. Cem. Concr. Compos. 2010, 32, 686-693. [CrossRef]

17. Sun, X.; Liao, W.; Kumar, A.; Khayat, K.H.; Tian, Z.; Ma, H. Multi-level modeling of thermal behavior of phase change material incorporated lightweight aggregate and concrete. Cem. Concr. Compos. 2021, 122, 104131. [CrossRef]

18. Wei, Y.; Gao, X.; Wang, F.; Zhong, Y. Nonlinear strain distribution in a field-instrumented concrete pavement slab in response to environmental effects. Road Mater. Pavement Des. 2019, 20, 367-380. [CrossRef]

19. Peyton, S.W.; Sanders, C.L.; John, E.E.; Hale, W.M. Bridge deck cracking: A field study on concrete placement, curing, and performance. Constr. Build. Mater. 2012, 34, 70-76. [CrossRef]

20. Zhang, J.; Wang, J.; Ding, X. Test and simulation on moisture flow in early age concrete under drying. Dry. Technol. 2018, 36, 221-233. [CrossRef] 
21. China Railway Corporation Standard. In QCR9202-2015, Code for Site Management of Railway Construction Project; China Railway Publishing House: Beijing, China, 2015.

22. Chinese Industrial Standard. In TB 10402-2019, Code for Construction Supervision of Railway Project; China Railway Publishing House: Beijing, China, 2019.

23. Hauggaard, A.B.; Damkilde, L.; Hansen, P.F. Transitional thermal creep of early age concrete. J. Eng. Mech. 1999, 125, 458-465. [CrossRef]

24. Bažant, Z.P.; Najjar, L.J. Nonlinear water diffusion in nonsaturated concrete. Matériaux Constr. 1972, 5, 3-20. [CrossRef]

25. Fib MC2010. Model Code for Concrete Structures 2010; Fédération International du Béton (FIB): Lausanne, Switzerland; Wilhelm Ernst \& Sohn: Berlin, Germany, 2013.

26. Bažant, Z.P.; Jirásek, M. Creep and Hygrothermal Effects in Concrete Structures; Springer: Dordrecht, The Netherlands, 2018.

27. Faria, R.; Azenha, M.; Figueiras, J.A. Modelling of concrete at early ages: Application to an externally restrained slab. Cem. Concr. Compos. 2006, 28, 572-585. [CrossRef]

28. Bažant, Z.P.; Hauggaard, A.B.; Baweja, S. Microprestress-solidification theory for concrete creep. II: Algorithm and verification. J. Eng. Mech. 1997, 123, 1195-1201. [CrossRef]

29. Wei, Y.; Guo, W.; Liang, S. Microprestress-solidification theory-based tensile creep modeling of early-age concrete: Considering temperature and relative humidity effects. Constr. Build. Mater. 2016, 127, 618-626. [CrossRef]

30. Wei, Y.; Liang, S.; Guo, W.; Hansen, W. Stress prediction in very early-age concrete subject to restraint under varying temperature histories. Cem. Concr. Compos. 2017, 83, 45-56. [CrossRef]

31. Wei, Y.; Liang, S.; Huang, J. Concrete creep modeling: Application to slabs on ground. J. Eng. Mech. 2019, $145,04019078$. [CrossRef]

32. Liao, G.Y.; Huang, X. Application of ABAQUS Finite Element Software in Road Engineering; Southeast University Publishing House: Nanjing, China, 2008. (In Chinese)

33. Pingrui, Z.; Xueyi, L.; Guan, L. Experimental study of temperature gradient in track slab under outdoor conditions in Chengdu area. J. Mod. Transp. 2014, 22, 148-155. [CrossRef]

34. Zeng, Z.; Wang, J.; Shen, S.; Ping, L.; Abdulmumin, A.S.; Wang, W. Experimental study on evolution of mechanical properties of CRTS III ballastless slab track under fatigue load. Constr. Build. Mater. 2019, 210, 639-649.

35. Yu, Z.; Xie, Y.; Tian, X. Research on mechanical performance of CRTS III plate-type ballastless track structure under temperature load based on probability statistics. Adv. Civ. Eng. 2019, 2019, 2975274. [CrossRef]

36. Wei, Y.; Hansen, W. Characterizing cracking potential of cementitious mixtures based on shrinkage and humidity drop rate. $A C I$ Mater. J. 2013, 110, 433-440. 